\title{
High-resolution wave and hydrodynamics modelling in coastal areas: operational applications for coastal planning, decision support and assessment
}

\author{
Achilleas G. Samaras ${ }^{1}$, Maria Gabriella Gaeta ${ }^{1}$, Adrià Moreno Miquel $^{2}$, and Renata Archetti $^{2}$ \\ ${ }^{1}$ CIRI - EC, Fluid Dynamics Unit, University of Bologna, Via del Lazzaretto 15/5, Bologna, 40131, Italy \\ ${ }^{2}$ Department of Civil, Chemical, Environmental and Materials Engineering, University of Bologna, Viale Risorgimento 2, \\ Bologna, 40136, Italy
}

Correspondence to: Achilleas G. Samaras (achilleas.samaras@unibo.it)

Received: 24 February 2016 - Published in Nat. Hazards Earth Syst. Sci. Discuss.: 4 March 2016

Revised: 20 May 2016 - Accepted: 23 May 2016 - Published: 1 July 2016

\begin{abstract}
Numerical modelling has become an essential component of today's coastal planning, decision support and risk assessment. High-resolution modelling offers an extensive range of capabilities regarding simulated conditions, works and practices and provides with a wide array of data regarding nearshore wave dynamics and hydrodynamics. In the present work, the open-source TELEMAC suite and the commercial software MIKE21 are applied to selected coastal areas of South Italy. Applications follow a scenario-based approach in order to study representative wave conditions in the coastal field; the models' results are intercompared in order to test both their performance and capabilities and are further evaluated on the basis of their operational use for coastal planning and design. A multiparametric approach for the rapid assessment of wave conditions in coastal areas is also presented and implemented in areas of the same region. The overall approach is deemed to provide useful insights on the tested models and the use of numerical models - in general - in the above context, especially considering that the design of harbours, coastal protection works and management practices in the coastal zone is based on scenario-based approaches as well.
\end{abstract}

\section{Introduction}

Accurate predictions of waves, currents and sea level variations in coastal areas are essential for a wide range of research and operational applications, as they govern inunda- tion, sediment and pollutant transport, coastal morphology evolution and interactions with structures. Accordingly, numerical models that can serve the above purposes have become the main tool for researchers, engineers and policymakers around the world involved in coastal planning, risk management and monitoring activities.

Following the above considerations, the development of reliable modelling systems or methods that can scale down from the ocean to the coastal scale has emerged as a need in today's research. Reliable information on the hydrodynamics of the zone defined as nearshore, in particular, can serve a key role in coastal planning and hazard mitigation, as relevant processes at that scale differ significantly from those described in larger-scale oceanographic models. It is self-evident that, in the above context, the capabilities and limitations of such systems and methods - apart from their structure - would depend on those of the numerical models they comprise.

A series of model coupling and nesting techniques, as well as entire methodological frameworks, has been proposed and applied in various research attempts for the development of modelling systems with the aforementioned characteristics. Among the early works on the subject, one can indicatively refer to Ozer et al. (2000), who proposed a coupling module for tides, surges and waves, applying it, however, to relatively low-resolution simulations for the North Sea. Regarding more recent and complete attempts, one can refer to the work of Warner et al. (2010), who developed the Coupled Ocean-Atmosphere-Wave-Sediment Transport 
system (COAWST); Ge et al. (2013), who developed the FVCOM system to simulate multi-scale dynamics at the East China Sea shelf and the Changjiang Estuary; and Barnard et al. (2014), who developed a modelling system for predicting storm impact on high-energy coasts (CoSMoS).

In contrast, integrated systems comprising atmosphere, ocean and coastal models do present a number of challenges for their users regarding both data interoperability and downscaling/nesting techniques, while they also demand significant computational expense in order to arrive to highresolution simulations near coasts. Furthermore, for a series of activities in coastal/marine planning (e.g. identification of wave energy sites, see Reikard, 2009; Bozzi et al., 2014), vulnerability/risk assessment (e.g. Stockdon et al., 2012; Idier et al., 2013; Archetti et al., 2016) and coastal protection measures/infrastructure design (e.g. van Duin et al., 2004; Burcharth et al., 2014; Karambas, 2014; Karambas and Samaras, 2014), either only parts of local hydrodynamics information are required (mainly wave properties to drive nearshore models) or the respective approaches are based on the study of frequent/extreme condition scenarios. Accordingly, a number of methods have been developed in order to estimate coastal wave properties from offshore information or largerscale simulations. One can refer to the early work of O'Reilly and Guza (1993), who proposed wave energy transformation coefficients based on the comparison of two spectral wave models' results or more recent ones using nesting and data assimilation schemes (Bertotti and Cavaleri, 2012; Rusu and Soares, 2014) and machine-learning techniques (Camus et al., 2011; Plant and Holland, 2011b, a). A work that stands out in recent literature is that of Long et al. (2014), who proposed a probabilistic method based on model scenarios for constructing wave time series at inshore locations.

The present work follows the rationale described above, comparing two modelling suites in the representation of nearshore dynamics and proposing a multiparametric scenario-based approach for the rapid assessment of wave conditions in coastal zones. Nevertheless, this work also served as the background study for the development of a modelling system coupling atmosphere, ocean and coastal dynamics, as described in Gaeta et al. (2016).

In the following, the open-source TELEMAC suite is compared with the well-known commercial software MIKE21 (developed by ${ }^{\circ}$ DHI Group) in fundamental wave/hydrodynamics modelling applications, aiming to test the models' performance and the representation of the various processes governing wave propagation and waveinduced nearshore hydrodynamics. The latter (i.e. MIKE21) is also used for the implementation of the aforementioned multiparametric approach based on a trilinear interpolation algorithm. The study areas for the presented applications are all located in South Italy and comprise the coastal area around the city/port of Brindisi, the coastal area around the city/port of Bari and the Gulf of Taranto (the latter only for the multiparametric approach's applications).
TELEMAC and MIKE21 results are compared on the basis of wave/current characteristics, along linear transects from the offshore to the nearshore and at specific points inside/outside the breaker zone and near harbour entrances (for the study area of Bari). As for the scenario-based approach, its background and formulation are presented in detail, along with its implementation in the framework of an operational system, supporting the rationale behind this study and setting the basis for future work on the same path.

\section{Methods}

\subsection{Wave and hydrodynamics modelling}

Wave modelling within the TELEMAC and MIKE21 suites is performed using TOMAWAC and MIKE21-SW respectively. TOMAWAC and MIKE21-SW are characterized as third-generation spectral wave models, as they do not require any parameterization on either the spectral or the directional distribution of power (or action density). The physical processes modelled comprise (a) energy source/dissipation processes (wind-driven interactions with atmosphere, dissipation through wave breaking/whitecapping/wave-blocking due to strong opposing currents, bottom friction-induced dissipation); (b) non-linear energy transfer conservative processes (resonant quadruplet interactions, triad interactions); and (c) wave propagation-related processes (wave propagation due to the wave group/current velocity, depth-/currentinduced refraction, shoaling, interactions with unsteady currents). The models compute the evolution of wave action density $N$ by solving the action balance equation (Booij et al., 1999):

$\frac{\partial N}{\partial t}+\nabla_{x, y}\left[\left(\boldsymbol{c}_{\mathrm{g}}+\boldsymbol{U}\right) N\right]+\frac{\partial}{\partial \sigma}\left(c_{\sigma} N\right)+\frac{\partial}{\partial \theta}\left(c_{\theta} N\right)=\frac{S_{\mathrm{tot}}}{\sigma}$,

where $N=E / \sigma, E$ being the variance density and $\sigma$ the relative angular frequency, $\boldsymbol{c}_{\mathrm{g}}$ is the intrinsic group velocity vector, $\boldsymbol{U}$ is the ambient current, $c_{\sigma}, c_{\theta}$ are the propagation velocities in spectral space $(\sigma, \theta)$ and $S_{\text {tot }}$ is the source/sink term that represents all physical processes which generate, dissipate or redistribute energy. Broken down to its components, $S_{\text {tot }}$ can be written as

$S_{\mathrm{tot}}=S_{\mathrm{in}}+S_{\mathrm{wc}}+S_{\mathrm{n} 14}+S_{\mathrm{bf}}+S_{\mathrm{br}}+S_{\mathrm{n} 13}$

where $S_{\text {in }}$ represents the energy transfer from wind to waves, $S_{\mathrm{wc}}$ the dissipation of energy due to whitecapping, $S_{\mathrm{n} 14}$ the nonlinear transfer of energy due to quadruplet (four-wave) interactions, $S_{\mathrm{bf}}$ the dissipation due to bottom friction, $S_{\mathrm{br}}$ the dissipation due to wave breaking and $S_{\mathrm{n} 13}$ the nonlinear transfer of energy due to triad (three-wave) interactions. TOMAWAC and MIKE-SW parameterize similarly the above processes; TOMAWAC, however, does offer more options regarding the available approaches/models to be used for most of them. Therefore, and regarding the processes 
of interest for the model intercomparison as presented in Sect. 3.1.3, the respective common approaches/models applied in this work are (i) the Battjes and Janssen (1978) model for bathymetric breaking; (ii) the model of Hasselmann et al. (1973) for bottom friction dissipation using a constant friction coefficient; (iii) the Komen et al. (1984) and Janssen (1991) dissipation model for whitecapping; and (iv) the LTA (Lumped Triad Approximation) model of Eldeberky and Battjes (1983) for triad interactions (the SPB model of Becq (1998) - available only in TOMAWAC is also tested). As for diffraction, its effect is simulated using the phase-decoupled approach proposed by Holthuijsen et al. (2003), based on the revised version of the Mild Slope Equation model of Berkhoff (1972) proposed by Porter (2003). Both models solve the governing equation by means of finite element-type methods to discretize geographical and spectral space, while the geographical domain is discretized by unstructured triangular meshes. Finally, and regarding specifically the coupling with 2-D hydrodynamics, it should be noted that the models compute and provide as output the four components of the radiation stress tensor, $S_{x x}, S_{y y}, S_{x y}$ and $S_{y x}$, evaluated by

$$
\begin{aligned}
& S_{x x}=\iint \frac{E}{2}\left[2 n(\cos \theta)^{2}+(2 n-1)\right] \mathrm{d} \sigma \mathrm{d} \theta, \\
& S_{y y}=\iint \frac{E}{2}\left[2 n(\sin \theta)^{2}+(2 n-1)\right] \mathrm{d} \sigma \mathrm{d} \theta, \\
& S_{x y}=S_{y x}=\iint E n \sin \theta \cos \theta \mathrm{d} \sigma \mathrm{d} \theta,
\end{aligned}
$$

as well as the respective wave-induced forces along the $x$ and $y$ axes (i.e. $F_{x}$ and $F_{y}$ ), evaluated by integrating the radiation stresses over the water depth.

Hydrodynamics modelling within the TELEMAC and MIKE21 suites is performed using TELEMAC-2D and MIKE21-HD respectively. The models solve the 2-D shallow water equations (also referred to as Saint-Venant equations; see Hervouet, 2007), derived by integrating the Reynoldsaveraged Navier-Stokes equations over the flow depth. Adopting the formulation of TELEMAC-2D for Cartesian coordinates, the equations of continuity and momentum along the $x$ and $y$ axes can be written as Eqs. (6), (7) and (8) respectively:

$$
\begin{aligned}
& \frac{\partial h}{\partial t}+\boldsymbol{u} \cdot \nabla(h)+h \operatorname{div}(\boldsymbol{u})=S_{\mathrm{h}} \\
& \frac{\partial u}{\partial t}+\boldsymbol{u} \cdot \nabla(u)=-g \frac{\partial \zeta}{\partial x}+S_{x}+\frac{1}{h} \operatorname{div}\left(h v_{t} \nabla u\right), \\
& \frac{\partial v}{\partial t}+\boldsymbol{u} \cdot \nabla(v)=-g \frac{\partial \zeta}{\partial y}+S_{y}+\frac{1}{h} \operatorname{div}\left(h v_{t} \nabla v\right),
\end{aligned}
$$

where $h$ is the water depth, $u, v$ are the velocity components and $\boldsymbol{u}$ the velocity vector, $g$ is the gravitational acceleration, $v_{t}$ is the momentum diffusion coefficient, $\zeta$ is the free surface elevation, $S_{\mathrm{h}}$ is a term representing sources/sinks of fluid and $S_{x}, S_{y}$ are terms representing sources/sinks of momentum within the domain (i.e. wind, Coriolis force, bottom friction, radiation stresses/forces from wave models). These primitive equations are solved by means of finite element/volume methods, while the geographical domain is discretized by unstructured triangular meshes. As also mentioned previously for TOMAWAC and MIKE-SW, and, although TELEMAC-2D and MIKE21-HD have a lot of similarities, TELEMAC-2D does offer more parameterization options regarding the definition of physical and numerical parameters. In the present work, the use of the hydrodynamics models is focused on the representation of wavegenerated currents a task achieved through their direct coupling - through radiation stresses - with the respective spectral wave models within the TELEMAC and MIKE21 suites (see Eqs. (3)-(8) in the previous).

\subsection{Multiparametric approach for the rapid assessment of nearshore wave conditions}

The methodology followed in the present work for the rapid assessment of nearshore wave conditions (within the framework set in the previous; see Sect. 1) comprises a number of steps aiming to establish an efficient and computationally reasonable approach for operational use. The approach is scenario-based; thus its first step consists in defining a number of scenarios representing wave conditions in the wider area of interest. This is done by performing a spectral analysis of sea surface elevation records from nearshore/offshore buoys in order to produce a data set of three aggregated wave parameters, namely the significant wave height $H_{\mathrm{s}}$, the peak period $T_{\mathrm{p}}$ and the mean wave direction $\mathrm{Dir}_{\mathrm{m}}$. Next, data set parameters are further divided into a number of classes each, forming by aggregation the sets of $H_{\mathrm{s}}-T_{\mathrm{p}}-\mathrm{Dir}_{\mathrm{m}}$, henceforth referred to as "scenarios". These scenarios are afterwards used (in sequence) as boundary conditions for the wave model runs, resulting in an extensive data set of model results for the entire computational domain, stored in ASCII files that are properly named on the basis of the input wave scenarios. These files form the high-resolution wave conditions database along with a query algorithm, serving as the "bridge" between coarser-resolution operational models and the aforementioned produced data set. The query algorithm is responsible for (a) identifying the boundary wave conditions given by the coarser-resolution model (as sets of $H_{\mathrm{s}}-T_{\mathrm{p}}-\mathrm{Dir}_{\mathrm{m}}$ ) and (b) scanning the data set for the ASCII file corresponding to the specific wave conditions and retrieving it. In the case that no data set file matches exactly the set of defined wave parameters, the algorithm will additionally (c) define the upper and lower classes' boundaries for all three parameters (i.e. $H_{\mathrm{s}}, T_{\mathrm{p}}$, $\operatorname{Dir}_{\mathrm{m}}$ ) on the basis of their original query values, scan the data set and retrieve the respective ASCII files, (d) implement a trilinear interpolation in the three-dimensional $H_{\mathrm{s}}-T_{\mathrm{p}}-\mathrm{Dir}_{\mathrm{m}}$ space (according to Bourke, 1999; Kreyszig, 2010) for each node of the computa- 
tional mesh and finally (e) store the derived parameter values in a new query-tailored ASCII file. The latter will represent the nearshore wave conditions for the query-defined set of wave parameters.

It should be noted that the division to a large number of parameter classes at the first steps of this approach will lead to a large number of scenarios and, consequently, a large number of runs to be performed by the coastal wave model, with the respective effect on computational cost. However, this will accordingly lead to a higher accuracy of the trilinear interpolation method as well, considering that its intrinsic error becomes lower with the increase in scenario discretization. Given that - in the framework of an operational system response speed is of the essence, the combination of the specific interpolation method with an adequately high number of defined scenarios is deemed to deliver the best performance overall due to its simplicity and implementation speed.

\section{Application set-up}

\subsection{Model intercomparison}

\subsubsection{Conceptual approach}

TELEMAC and MIKE21 have been extensively used over the years in research, operational and engineering design applications in maritime/coastal hydraulics; for MIKE21 this use leans significantly towards the last two categories, it being one of the most widespread commercial suites for relevant applications. Their models have been separately evaluated and validated for several case studies. Regarding TELEMAC, exemplary reference can be made to the work of Brière et al. (2007) on assessing its performance for a hydrodynamic case study; Brown and Davies (2009), Luo et al. (2013) and Villaret et al. (2013) on coupled wave/hydrodynamics-sediment transport/morphological modelling; Sauvaget et al. (2000) on the modelling of tidal currents; and Jia et al. (2015) on wavecurrent interactions in a river- and wave-dominant estuary. Regarding MIKE21, respective literature review would include the work of Siegle et al. (2007) and Ranasinghe et al. (2010) on coupled wave/hydrodynamics-sediment transport/morphological modelling, Babu et al. (2005) on the modelling of tide-driven currents, Kong (2014) on the impact of tidal waves on storm surge and Aboobacker et al. (2009) and AriGüner et al. (2013) on wave modelling. However, and given the fact that regarding system architecture and modelling components TELEMAC and MIKE21 have a lot of similarities (see also Sect. 2.1), literature has to show limited references on their comparative evaluation.

The rationale behind the model intercomparison presented in the following derives from the general framework within which this work is carried out, that is the use of highresolution wave and hydrodynamics models for (a) the de- velopment and application of a multiparametric approach for the rapid assessment of wave conditions at inshore locations (presented in Sects. 2.2 and 3.2) and (b) the development of a modelling system coupling atmosphere, ocean and coastal dynamics (presented in Gaeta et al., 2016). Accordingly, the TELEMAC and MIKE21 suites are compared in fundamental wave-hydrodynamics modelling applications, aiming to test models' performance and the representation of the various processes governing wave propagation and waveinduced nearshore hydrodynamics. The comparison is performed for both single wave events and time series or random waves, representative of typical applications for coastal planning, decision support and assessment. Apart from a coastal stretch near the city and harbour of Brindisi, applications (using only TOMAWAC) are also performed for the area around the city of Bari, including its harbour. Specifically regarding the latter - and given the inherent limitations posed by the inclusion of diffraction in phase-averaged models - it should be noted that the objective was solely to test the extent to which spectral models like TOMAWAC could be used to capture diffraction effects near harbour entrances (when the detailed agitation inside the harbour is not of interest), without the need to resort to separate time-demanding applications using phase-resolving models. The intercomparison also retains a strong user-oriented component, presenting examples of how models perform under typical coastal application scenarios and how basic physical processes affect the computed parameters of interest.

\subsubsection{Study areas and mesh generation}

The first of the two study areas is located northwest of the city of Brindisi (South Italy), comprising Torre Guaceto, a marine protected area and state natural reserve of significant importance. The selected rectangular outline of the domain for the model applications measures about $21 \mathrm{~km}$ in the longshore and $7.5 \mathrm{~km}$ in the cross-shore direction; Fig. 1a shows the wider study area and the aforementioned outline. The second study area comprises the coastal area around the city and harbour of Bari (South Italy); the outline of the computational domain in this case measures about $16.5 \mathrm{~km}$ in the longshore and $8.5 \mathrm{~km}$ in the cross-shore direction (see Fig. 1b).

As mentioned in Sect. 2.1, both the TELEMAC and MIKE21 modelling suites discretize the computational domain by unstructured triangular meshes. Mesh generation for TELEMAC applications was done using Blue Kenue, a data preparation, analysis and visualization tool for hydraulic modellers developed by the National Research Council of Canada; the respective work for MIKE21 was done using MIKE Zero, the DHI tool for managing MIKE projects.

The bathymetric and shoreline data used in this work resulted from the digitization of nautical charts acquired from the Italian National Hydrographic Military Service ("Istituto Idrografico della Marina Militare”). For the case study 

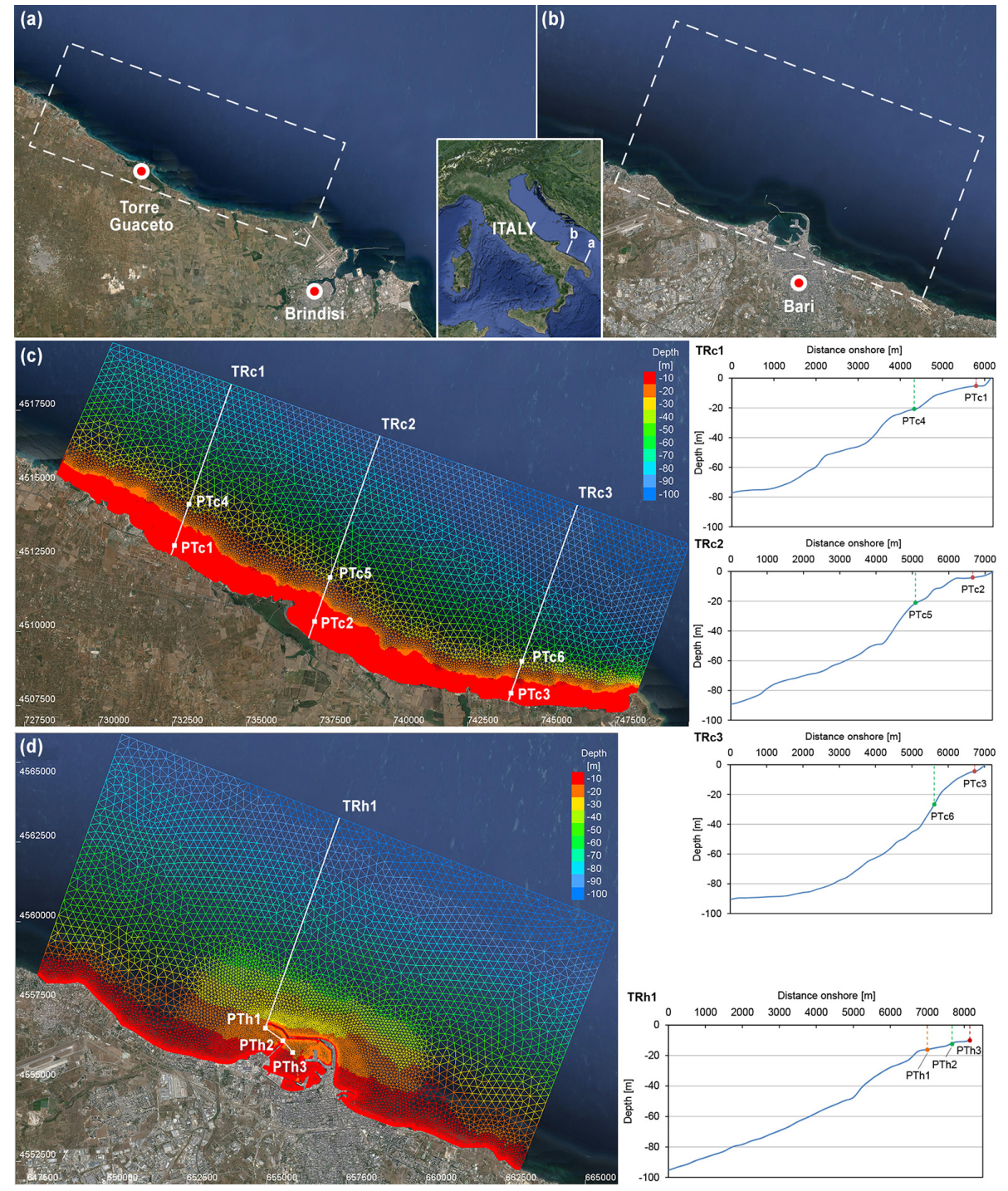

Figure 1. Satellite images of the wider areas, outlines of the computational domains, meshes, bathymetries, linear transects and points for results' analysis for the Brindisi-Torre Guaceto (a, c) and Bari (b, d) case studies (background images from Google Earth, 2016; privately processed).

of Brindisi-Torre Guaceto the triangular mesh was created defining two density zones $(20 \mathrm{~m}$ edge length below the $-10 \mathrm{~m}$ isoline and $250 \mathrm{~m}$ for the rest of the field), resulting in a mesh consisting of 55340 nodes forming 109124 elements. It should be noted that the mesh was first created in Blue Kenue and afterwards properly transformed to MIKE Zero format, maintaining the exact same nodes and connections in order to exclude mesh-dependent divergences in the model runs. Figure 1c shows the mesh and bathymetry of the computational domain, along with the three linear transects and six points for which model results will be intercompared (see Sect. 3.1.3). For the case study of Bari, three density zones were defined arriving to the finest discretization of $10 \mathrm{~m}$ edge length in order to represent harbour structures, $250 \mathrm{~m}$ being the lowest discretization moving offshore. The resulting mesh consists of 25202 nodes forming 46144 elements; Fig. 1d shows the mesh and bathymetry of the computational domain, along with the linear transect and three points used for results' analysis (see Sect. 3.1.3).

\subsubsection{Application set-up for model intercomparison}

Table 1 presents a detailed overview of all model runs; the table is divided in two parts, the top one referring to the Brindisi-Torre Guaceto applications and the bottom one to the Bari applications (see also Fig. 1). Runs for the BrindisiTorre Guaceto case study refer to coupled wave and hydrodynamics models applications, that is coupled TOMAWACTELEMAC-2D and MIKE21-SW-MIKE21-HD runs for the TELEMAC and MIKE21 suites respectively. Runs for the 
Table 1. Overview of TELEMAC and MIKE21 model runs.

\begin{tabular}{|c|c|c|c|c|c|c|}
\hline & Run & Forcing & Processes & Comparison along/at & Compared parameters & Figure(s) \\
\hline \multirow{4}{*}{ 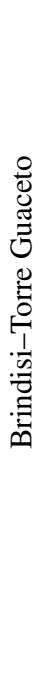 } & $\begin{array}{l}\text { Tc11 } \\
\text { Tc12 } \\
\text { Tc13 } \\
\text { Tc14 }\end{array}$ & WE1 & $\begin{array}{l}\text { PRc1 } \\
\text { PRc2 } \\
\text { PRc3 } \\
\text { PRc4 }\end{array}$ & TRc1, TRc2, TRc3 & $H_{\mathrm{s}}, T_{\mathrm{m}}, \operatorname{Dir}_{\mathrm{m}}{ }^{\mathrm{b}}$ & 5,6 \\
\hline & $\begin{array}{l}\text { Tc21 } \\
\text { Tc22 } \\
\text { Tc23 } \\
\text { Tc24 }\end{array}$ & WE2 & $\begin{array}{l}\text { PRc1 } \\
\text { PRc2 } \\
\text { PRc3 } \\
\text { PRc4 }\end{array}$ & TRc1, TRc2, TRc3 & $H_{\mathrm{s}}, T_{\mathrm{m}}, \operatorname{Dir}_{\mathrm{m}}$ & 7,8 \\
\hline & $\begin{array}{l}\text { Tc31 } \\
\text { Tc32 } \\
\text { Tc33 } \\
\text { Tc34 }\end{array}$ & TS1 & $\begin{array}{l}\text { PRc1 } \\
\text { PRc2 } \\
\text { PRc3 } \\
\text { PRc4 }\end{array}$ & $\begin{array}{l}\text { PTc1, РTc2, РTc3, } \\
\text { PTc4, PTc5, PTc6 }\end{array}$ & $\begin{array}{l}H_{\mathrm{S}} \\
\text { Curr. speed/direction }{ }^{\mathrm{c}}\end{array}$ & $\begin{array}{l}9 \\
10\end{array}$ \\
\hline & $\begin{array}{l}\text { Tc41 } \\
\text { Tc42 } \\
\text { Tc43 } \\
\text { Tc44 }\end{array}$ & TS2 & $\begin{array}{l}\text { PRc1 } \\
\text { PRc2 } \\
\text { PRc3 } \\
\text { PRc4 }\end{array}$ & $\begin{array}{l}\text { PTc1, РTc2, PTc3, } \\
\text { PTc4, PTc5, PTc6 }\end{array}$ & $\begin{array}{l}H_{\mathrm{S}} \\
\text { Curr. speed/direction }{ }^{\mathrm{c}}\end{array}$ & $\begin{array}{l}11 \\
12\end{array}$ \\
\hline \multirow{4}{*}{ 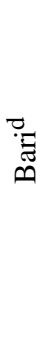 } & $\begin{array}{l}\text { Th1 } \\
\text { Th1D }\end{array}$ & WE1 & $\begin{array}{l}\text { PRh1 } \\
\text { PRh2 }\end{array}$ & TRh1 & $H_{\mathrm{s}}, T_{\mathrm{m}}, \operatorname{Dir}_{\mathrm{m}}$ & 13 \\
\hline & $\begin{array}{l}\text { Th2 } \\
\text { Th2D }\end{array}$ & WE2 & $\begin{array}{l}\text { PRh1 } \\
\text { PRh2 }\end{array}$ & TRh1 & $H_{\mathrm{s}}, T_{\mathrm{m}}, \operatorname{Dir}_{\mathrm{m}}$ & 13 \\
\hline & $\begin{array}{l}\text { Th3 } \\
\text { Th3D }\end{array}$ & TS1 & $\begin{array}{l}\text { PRh1 } \\
\text { PRh2 }\end{array}$ & PTh1, PTh2, PTh3 & $H_{\mathrm{s}}, T_{\mathrm{m}}, \operatorname{Dir}_{\mathrm{m}}$ & 14 \\
\hline & $\begin{array}{l}\text { Th4 } \\
\text { Th4D }\end{array}$ & $\mathrm{TS} 2$ & $\begin{array}{l}\text { PRh1 } \\
\text { PRh2 }\end{array}$ & PTh1, PTh2, PTh3 & $H_{\mathrm{s}}, T_{\mathrm{m}}, \operatorname{Dir}_{\mathrm{m}}$ & 14 \\
\hline
\end{tabular}

a TELEMAC-only run (see Sections 2.1 and 3.1.1).

${ }^{\mathrm{b}} H_{\mathrm{S}}$ is significant wave height, $T_{\mathrm{m}}$ is mean wave period, $\mathrm{Dir}_{\mathrm{m}}$ is mean wave direction.

$\mathrm{c}$ Current speed/direction are intercompared only at PTc1, PTc2 and PTc3.

${ }^{\mathrm{d}}$ Stand-alone TOMAWAC runs (see Sects. 2.1 and 3.1.1).

Bari case study refer to stand-alone TOMAWAC applications, in the framework of the conceptual approach as presented in Sect. 3.1.1. Every model run is assigned a different codename, henceforth used for its identification, with each line of Table 1 defining the forcing used (i.e. single wave events or time series of random waves); the processes included in the wave models' set-up (see Table 2 and Sect. 2.1); the transects along which or the points at which results are intercompared; the parameters included in the comparison; and, finally, a reference to the figure(s) presenting the specific results in Sect. 4.

The forcings were selected to represent a wide range of conditions regarding the wave climate in the areas of interest. The two single wave events selected, henceforth denoted as WE1 and WE2, represent the 50- and 2-year return period waves as resulted from the analysis of Regione Puglia (2009). The two $12 \mathrm{~h}$ time series selected, henceforth denoted as TS1 and TS2, were identified after analysis of wave data from the buoy of Monopoli (lat/long: $40^{\circ} 58.5^{\prime} \mathrm{N}, 17^{\circ} 22.6^{\prime} \mathrm{E}$; depth: $90 \mathrm{~m}$ ), part of the Italian wave metric network RON ("Rete
Table 2. Definition of the processes included in TELEMAC and MIKE21 spectral wave models' set-up (see Table 1).

\begin{tabular}{|c|c|c|c|c|c|}
\hline Processes & Breaking & $\begin{array}{l}\text { Bottom } \\
\text { friction }\end{array}$ & Whitecapping & $\begin{array}{l}\text { Triads } \\
\text { (LTA) }\end{array}$ & $\begin{array}{l}\text { Triads } \\
\text { (SPB) }\end{array}$ \\
\hline \multicolumn{6}{|c|}{ Brindisi-Torre Guaceto } \\
\hline PRc1 & $\sqrt{ }$ & $\sqrt{ }$ & & & \\
\hline PRc2 & $\sqrt{ }$ & $\sqrt{ }$ & $\sqrt{ }$ & & \\
\hline PRc3 & $\sqrt{ }$ & $\sqrt{ }$ & $\sqrt{ }$ & $\sqrt{ }$ & \\
\hline $\mathrm{PRc} 4^{\mathrm{a}}$ & $\sqrt{ }$ & $\sqrt{ }$ & $\sqrt{ }$ & & $\sqrt{ }$ \\
\hline \multicolumn{6}{|l|}{ Bari $^{b}$} \\
\hline Processes & Breaking & $\begin{array}{l}\text { Bottom } \\
\text { friction }\end{array}$ & Diffraction & & \\
\hline PRh1 & $\sqrt{ }$ & $\sqrt{ }$ & & & \\
\hline PRh2 & $\sqrt{ }$ & $\sqrt{ }$ & $\sqrt{ }$ & & \\
\hline
\end{tabular}

a Processes applied only to TELEMAC runs as Triads (SPB) are available only in TOMAWAC (see Sects. 2.1 and 3.1.1).

$\mathrm{b}$ Processes applied to stand-alone TOMAWAC runs (see Sects. 2.1 and 3.1.1). 

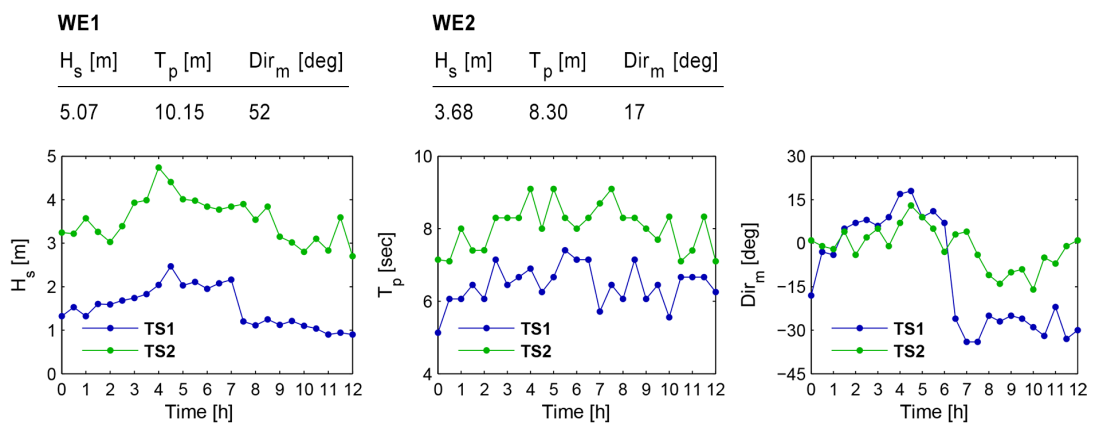

Figure 2. Characteristics of the wave events (WE1, WE2) and time series (TS1, TS2) used as forcings for TELEMAC and MIKE21 runs (see also Table 1).

Ondametrica Nazionale"; Corsini et al., 2006). All their characteristics are presented in Fig. 2.

The processes included in the wave models' set-up are presented in Sect. 2.1. It should be highlighted that each of these common processes (also presented in Table 2) was included in the set-up of TOMAWAC and MIKE21-SW using the same parameterizations. Energy transfer from wind to waves (term $S_{\text {in }}$ in Eq. 2) and nonlinear energy transfer due to quadruplet (four-wave) interactions (term $S_{\mathrm{n} 14}$ in Eq. 2) were not included, as their effects on spectral evolution would have been insignificant for the model intercomparison as it has been set-up on the basis of the rationale presented in Sect. 3.1.1 (i.e. focus on the nearshore, dictating the relatively small size of the computational domain in the cross-shore direction).

Considering that model results presented over the entire computational domain (as 2-D fields of the respective parameters) would pose significant challenges to the perceptibility of any intercomparison attempt (between both different modelling suites and different processes), it was deemed preferable to compare model results along linear transects from the offshore computational boundary to the shoreline (for WE1 and WE2) or at specific points (for TS1 and TS2). For the Brindisi-Torre Guaceto case study, transects TRc1, TRc2 and TRc3 were defined in order to capture areas of different/representative bathymetry profiles alongshore; the pairs of points PTc1-PTc4, PTc2-PTc5 and PTc3-PTc6 were defined at specific locations of the aforementioned transects respectively. The first point of each of the previous pairs was selected to fall within the breaker zone and second one before the breaker line; given that - regarding the hydrodynamics the objective was to compare wave-generated currents, the hydrodynamics models' results were analysed only at points PTc1, PTc2 and PTc3. The locations of the points were decided to not change between runs for different forcings, in order to facilitate the comprehensibility of the presented results. For the Bari case study, the objective being to test the diffraction algorithm's performance in spectral wave models (see also Sect. 3.1.1), one transect was defined (TRh1) and three points along it: one at the vicinity of the outer break- water tip (PTh1), one right at the middle of the harbour's entrance (PTh2) and one inside the harbour close to the entrance (PTh3). All transects, points and bathymetric profiles are presented in Fig. 1c and d.

\subsection{Multiparametric approach for the rapid assessment of wave conditions}

The multiparametric approach presented in this work was applied to three areas of interest in South Italy: the areas around the cities/ports of Brindisi and Bari, as well as the Gulf of Taranto (see Fig. 3). Accordingly, the scenarios representing wave conditions in the wider area were defined based on the analysis of data from the buoys of Monopoli (lat/long: $40^{\circ} 58.5^{\prime} \mathrm{N}, 17^{\circ} 22.6^{\prime} \mathrm{E}$; depth: $90 \mathrm{~m}$; see Fig. 3) and Crotone (lat/long: $39^{\circ} 01.4^{\prime} \mathrm{N}, 17^{\circ} 13.2^{\prime} \mathrm{E}$; depth: $95 \mathrm{~m}$; see Fig. 3), covering the period from 1 January 1989 to 31 December 2012. For each buoy data set, wave parameters were further divided into a number of classes each - according to Table 3 - forming by aggregation the scenarios to be used for the wave model runs (i.e. sets of $H_{\mathrm{s}}-T_{\mathrm{p}}-\mathrm{Dir}_{\mathrm{m}}$ ). Figure $4 \mathrm{a}$ and $\mathrm{b}$ show the frequencies of occurrence of the scenarios' $H_{\mathrm{s}}-T_{\mathrm{p}}$ and $H_{\mathrm{s}}-\mathrm{Dir}_{\mathrm{m}}$ pairs respectively for the Monopoli data set; Fig. $4 \mathrm{c}$ and $\mathrm{d}$ show the respective frequencies for Crotone. It should be noted that all directions follow the nautical direction convention; negative values were used in Fig. $4 \mathrm{~b}$ for representation issues, as gaps in certain direction ranges (i.e. corresponding to what would be seaward wave origins) were omitted.

Simulations were performed using MIKE-SW, the spectral wave model of the MIKE21 suite (see description in Sect. 2.1). Mesh generation was done using MIKE Zero (Fig. 3 shows the modelling domains' outlines); the overall set-up methodology is described in Sect. 3.1, including the processes of energy dissipation due to bathymetric breaking and bottom friction. The previously defined scenarios were used - in sequence - as boundary conditions for the model runs; the scenarios resulted from the Monopoli data set were used in the Brindisi and Bari runs, while the ones from the Crotone data set in the Gulf of Taranto runs. Model 


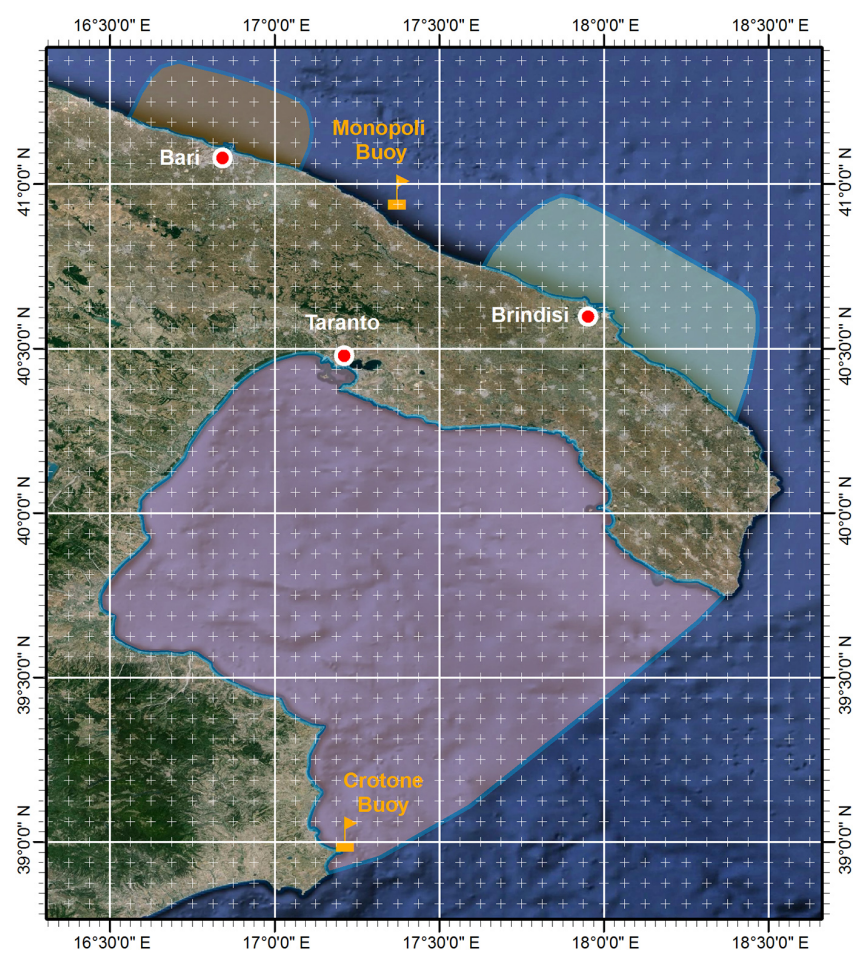

Figure 3. Computational domain outlines for the three areas in South Italy where the proposed multiparametric approach was applied and locations of the Monopoli and Crotone buoys; the grid lines and points represent the WAVEWATCH III rectilinear grid (background image from Google Earth (2016); privately processed).

Table 3. Class properties applied to the wave parameter data sets for scenarios' definition.

\begin{tabular}{llll}
\hline Parameter & Minimum & Maximum & Class step \\
\hline$H_{\mathrm{s}}(\mathrm{m})$ & 0.1 & 6 & 0.1 \\
$T_{\mathrm{p}}(\mathrm{s})$ & 1.5 & 12 & 0.5 \\
$\operatorname{Dir}_{\mathrm{m}}\left({ }^{\circ}\right)$ & 0 & 355 & 5 \\
\hline
\end{tabular}

results created three extensive data sets (one for each study area), stored in properly named ASCII files, as described in Sect. 2.2. The performance of the developed query algorithm, also described in Sect. 2.2, was tested for a series of exemplary cases before its operational implementation.

In the framework of the Research Project "TESSA" (Development of Technologies for the Situational Sea Awareness), the specific multiparametric approach was applied using WAVEWATCH III (Tolman, 2009) as the coarserresolution model that would feed sets of $H_{\mathrm{s}}-T_{\mathrm{p}}-\operatorname{Dir}_{\mathrm{m}}$ to the query algorithm in order to retrieve/create the nearshore wave conditions file (based on MIKE-SW results); the model's rectilinear grid is presented in Fig. 3.
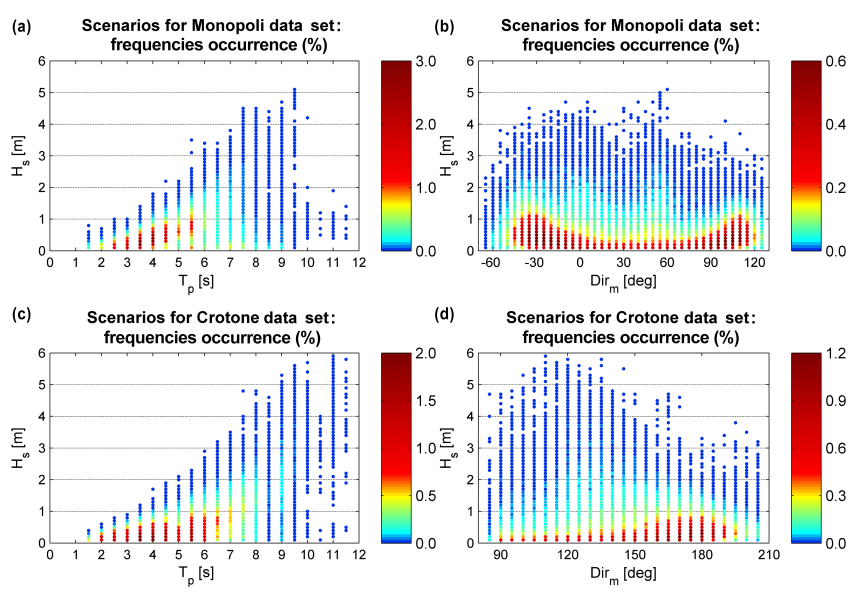

Figure 4. Frequencies of occurrence of the scenarios' $H_{\mathrm{s}}-T_{\mathrm{p}}$ and $H_{\mathrm{s}}-\operatorname{Dir}_{\mathrm{m}}$ pairs for the Monopoli data set (a and $\mathbf{b}$ respectively) and the Crotone data set (c and $\mathbf{d}$ respectively).

\section{Results and discussion}

As described in Sect. 3.1 and presented in Tables 1 and 2, model intercomparison regards the Brindisi-Torre Guaceto case study. Figures 5 and 6 show the comparison of TELEMAC and MIKE2 1 results $\left(H_{\mathrm{s}}-T_{\mathrm{m}}-\mathrm{Dir}_{\mathrm{m}}\right)$ along transects TRc1, TRc2 and TRc3 for forcing WE1, as well as the effect of different processes on $H_{\mathrm{S}}$ along the specific transects, separately for each modelling suite; Figs. 7 and 8 show the respective results for forcing WE2. The overall agreement between model results is good, and all parameters are very close for the majority of runs for both forcings, with a general observation being that TELEMAC constantly produces slightly higher values of $H_{\mathrm{s}}$ and lower values of $T_{\mathrm{m}}$ than MIKE21. The extensive set of runs tested allows for a more detailed analysis of the models' performance, as presented in the following. For runs Tc11 and Tc21, including the processes of breaking and bottom friction dissipation, $H_{\mathrm{s}}$ values are practically overlapping along most part of all three transects, with the exception of the divergences observed at the vicinity of the breaker line (more noticeable for the relatively mild slope TRc1 rather than TRc2 and TRc3); $T_{\mathrm{m}}$ and $\mathrm{Dir}_{\mathrm{m}}$ show small divergences as well, mostly noticeable after breaking for the steeper slope profiles of TRc2 and TRc3 and for the higher-wave forcing WE1 (i.e. Tc11 run). The inclusion of the process of energy dissipation due to whitecapping in runs Tc12 and Tc22 results in a small decrease of $H_{\mathrm{s}}$ overall, which is more clearly noticeable in Figs. $6 \mathrm{~b}$ and $8 \mathrm{~b}$ presenting such effects separately for TELEMAC and MIKE21; changes in $T_{\mathrm{m}}$ and $\mathrm{Dir}_{\mathrm{m}}$ are barely noticeable between Tc11Tc12 and Tc21-Tc22 runs. The additional inclusion of the non-linear triad interactions in runs Tc13 and Tc23 leads to the most noticeable discrepancies between model results (again, more noticeable for the relatively mild slope TRc1 rather than TRc2 and TRc3), which is limited (as expected) 

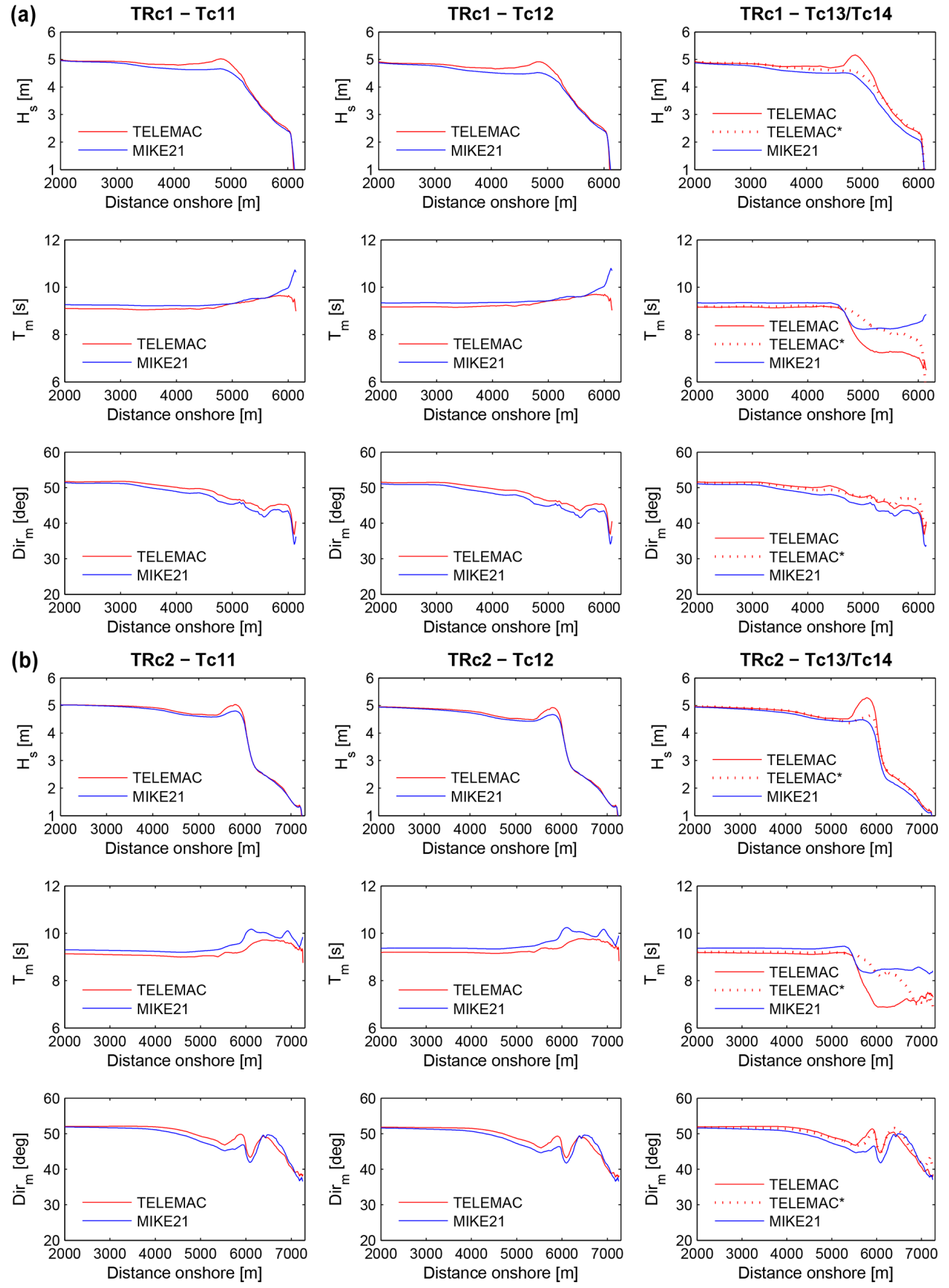

Figure 5. Comparison of TELEMAC and MIKE21 results $\left(H_{\mathrm{s}}-T_{\mathrm{m}}-\mathrm{Dir}_{\mathrm{m}}\right)$ along transects (a) TRc1 and (b) TRc2, for the Brindisi-Torre Guaceto case study (forcing WE1; $\left.{ }^{*}=\mathrm{Tc} 14\right)$.

to the shallow water sections of the studied profiles/transects where the specific process's effect becomes significant. Although both suites use the LTA model of Eldeberky and Battjes (1983), the inclusion of triads seems to have a rather small effect on MIKE21 $H_{\mathrm{s}}$ results (slight decrease of wave height and shift of the breaker line seaward), with the effect on the wave energy spectrum, however, becoming more evident when comparing $T_{\mathrm{m}}$ values. In contrast, TELEMAC runs result in higher $H_{\mathrm{s}}$ values right before breaking and quite lower $T_{\mathrm{m}}$ values inshore. Dir $_{\mathrm{m}}$ results show small divergences for both modelling suites. Additionally to runs Tc13 and $\mathrm{Tc} 23$, the effect of triad interactions was also tested using the SPB model of Becq (1998), available as an alternative option only in TOMAWAC; the test was included as 

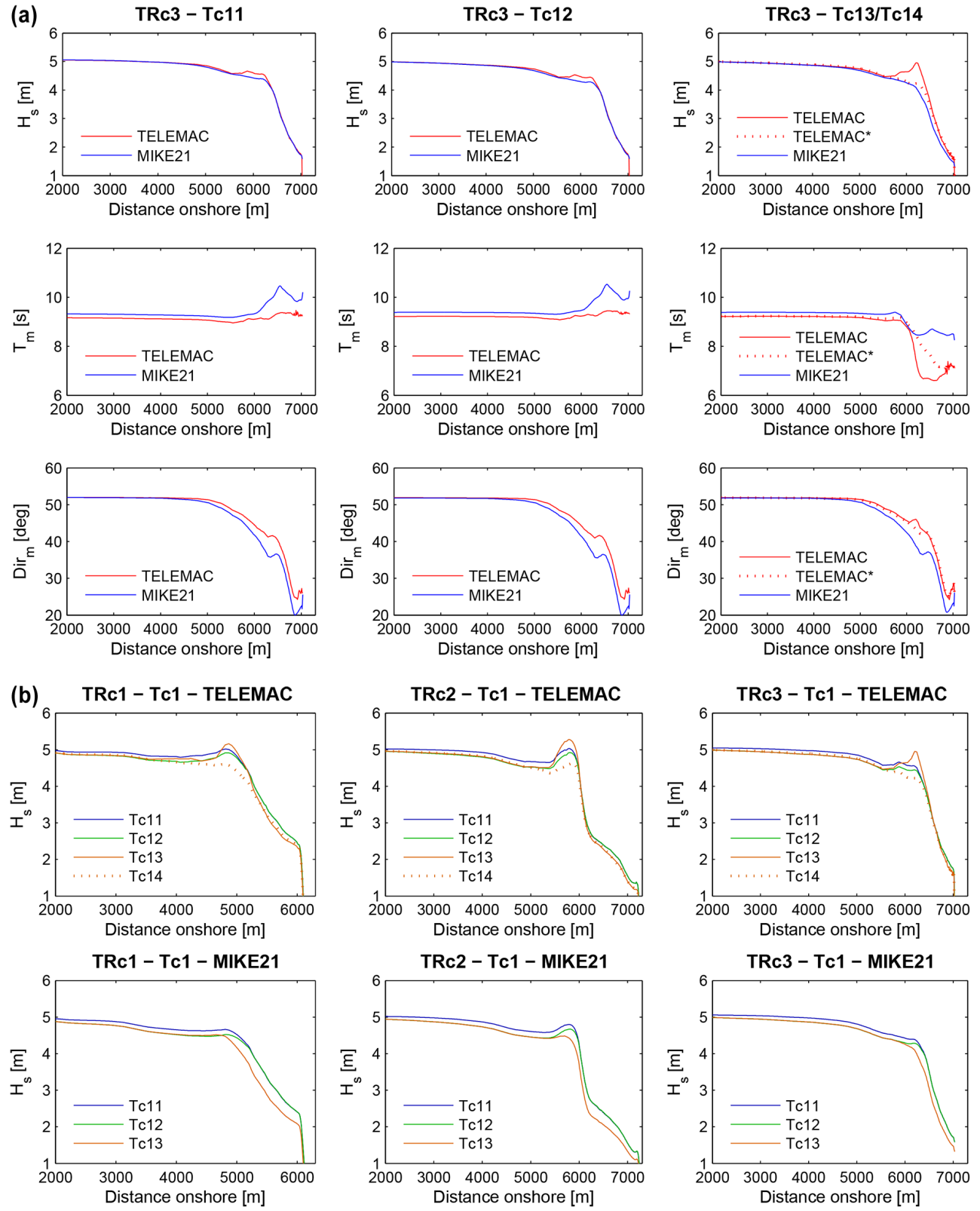

Figure 6. (a) Comparison of TELEMAC and MIKE21 results $\left(H_{\mathrm{s}}-T_{\mathrm{m}}-\mathrm{Dir}_{\mathrm{m}}\right)$ along transect TRc3 for the Brindisi-Torre Guaceto case study (forcing WE1; * $=$ Tc14); (b) effect of different processes on $H_{\mathrm{S}}$ for TELEMAC (top) and MIKE21 (bottom).

Tc14 in the set of runs, and its results are represented as dotted lines in all figures (noted accordingly). Following BecqGirard et al. (1999) remarks on the validity range of the LTA model, Tc14 results show indeed a quite different representation of the process by TOMAWAC, with milder evolution of the wave energy onshore and smaller changes to all parameter values than $\mathrm{Tc} 13$ produced (see Figs. $6 \mathrm{~b}$ and $8 \mathrm{~b}$ in particular).

Figures 9 and 10 show the comparison of TELEMAC and MIKE21 results ( $H_{\mathrm{S}}$ and Curr. speed/direction respectively), for the time series forcing TS1; Figs. 11 and 12 show the respective results for forcing TS2. Significant wave height values are compared at points along transects TRc1, TRc2 and TRc3 (see Fig. 1), three of them within the breaker zone (PTc1, PTc2, PTc3) and three outside of it (PTc4, PTc5, PTc6); the wave-generated currents' speed and direction are compared only at points PTc1, PTc2 and PTc3 (see also Sect. 3.1.3). Regarding $H_{\mathrm{s}}$, the comparison between results at pairs PTc1-PTc4, PTc2-PTc5 and PTc3-PTc6 highlights the effect different processes have on model results for propagating waves towards the nearshore and how including/omitting them may become significant (or insignif- 

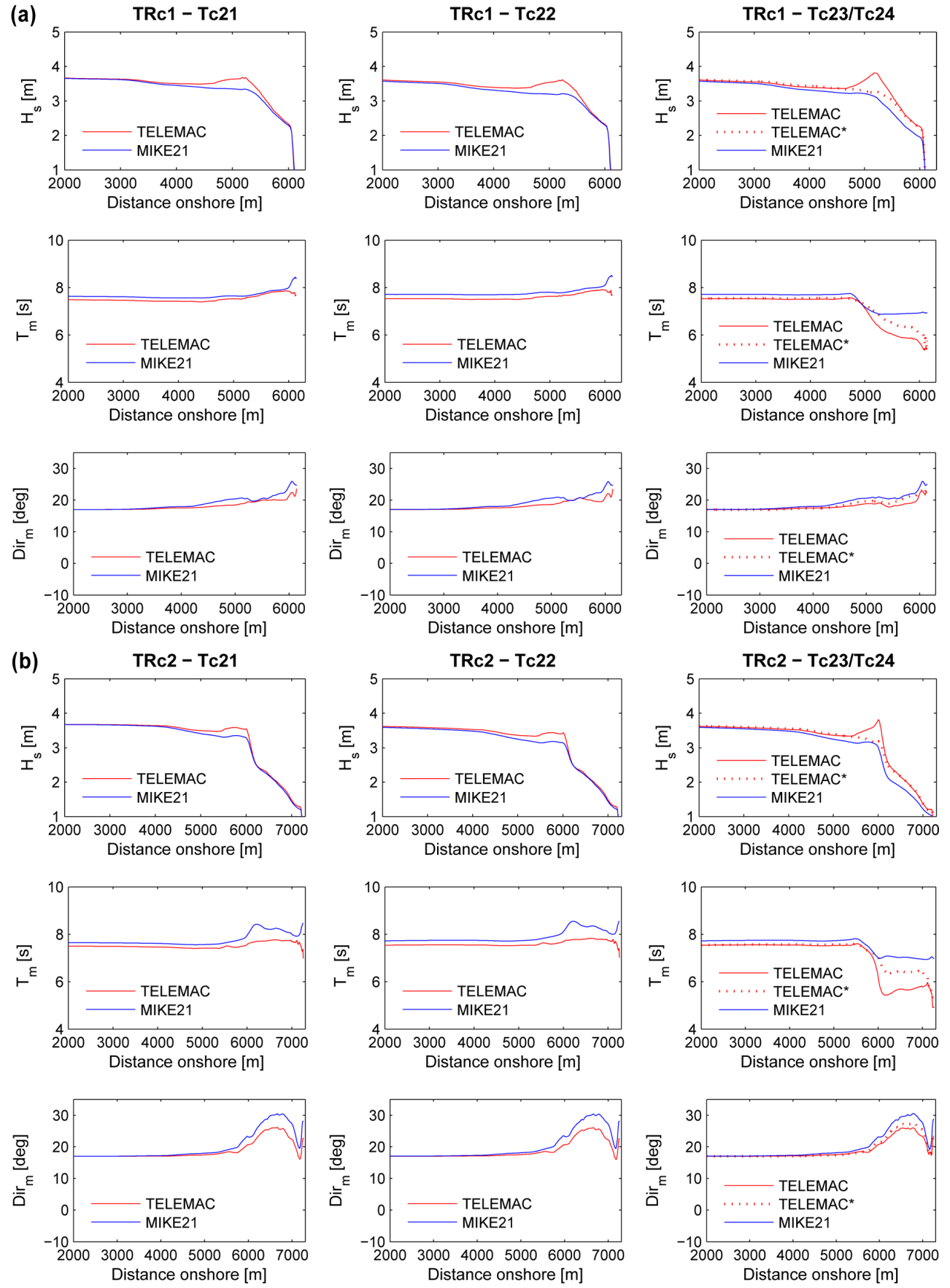

Figure 7. Comparison of TELEMAC and MIKE21 results $\left(H_{\mathrm{s}}-T_{\mathrm{m}}-\mathrm{Dir}_{\mathrm{m}}\right)$ along transects (a) TRc1 and (b) TRc2, for the Brindisi-Torre Guaceto case study (forcing WE2; ${ }^{*}=\mathrm{Tc} 24$ ).

icant) for various operational, planning and engineering design applications in coastal areas. TELEMAC and MIKE21 results at points PTc4, PTc5 and PTc6 are close and inphase for all processes, with higher discrepancies observed for the higher-wave forcing TS2. At points PTc1, PTc2 and $\mathrm{PTc} 3$, the conclusions drawn from the analysis of the wave events' results in the previous can be clearly identified here as well, with the most significant alterations in the different suites' results observed again for the runs where triad interactions were included in the modelled processes (i.e. Tc33/Tc34 and Tc43/Tc44); it should be also noted that the higher-wave forcing TS2 leads to smaller variations of $H_{\mathrm{s}}$ than TS1 overall, thus minimizing the effect of the different approach for triads modelling in run Tc44 too. Regard- 

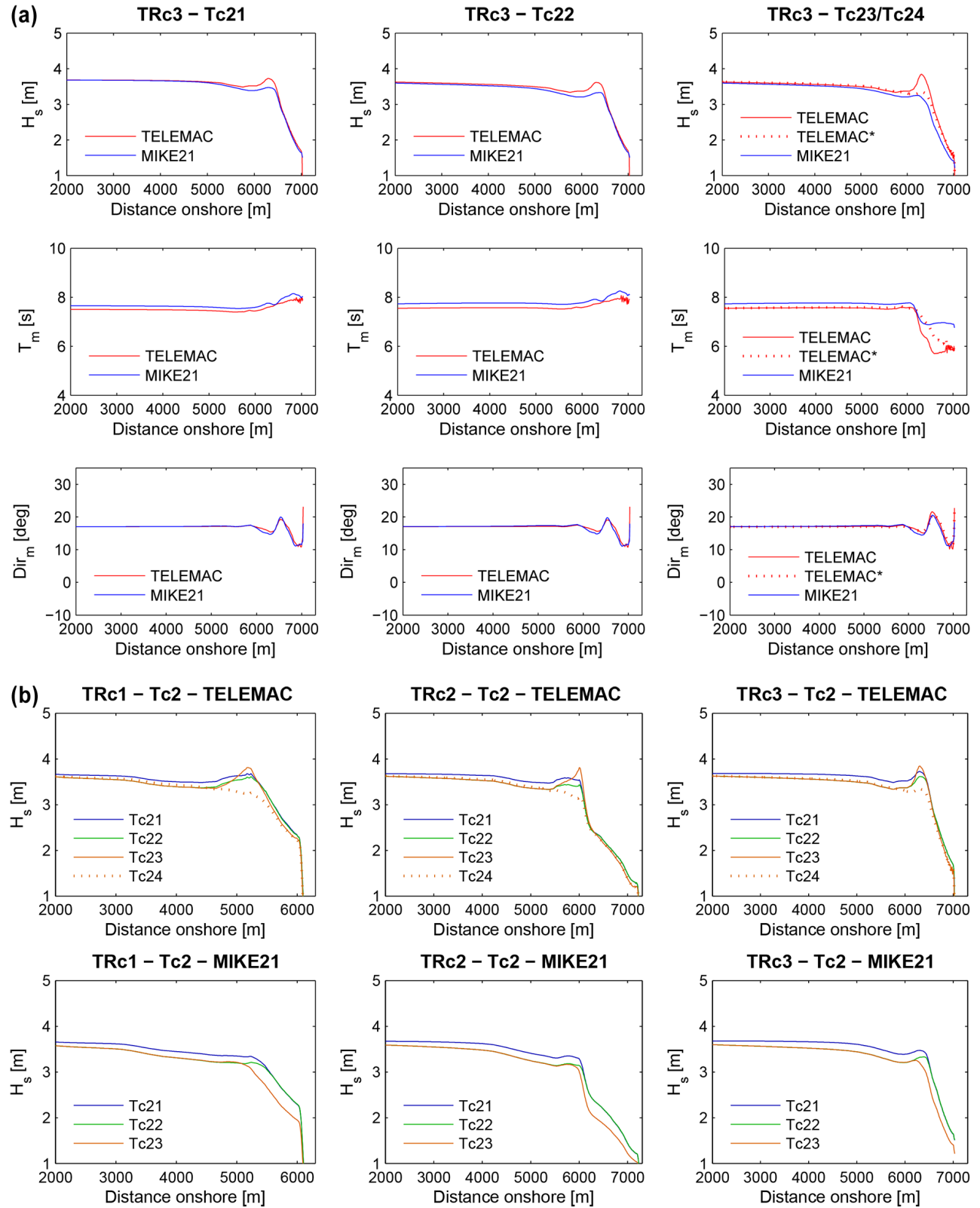

Figure 8. (a) Comparison of TELEMAC and MIKE21 results $\left(H_{\mathrm{s}}-T_{\mathrm{m}}-\mathrm{Dir}_{\mathrm{m}}\right)$ along transect TRc3 for the Brindisi-Torre Guaceto case study (forcing WE2; * $=$ Tc24); (b) effect of different processes on $H_{\mathrm{S}}$ for TELEMAC (top) and MIKE21 (bottom).

ing the wave-generated currents, TELEMAC and MIKE21 results are in relatively good agreement for all runs considering the order of magnitude of the resulting current speeds, as well as the sensitivity of current directions within the breaking zone. Figure 10 shows that for runs Tc31 and Tc32 results are very close with the exception of the period up to hour 4 at PTc1, where TELEMAC shows current speeds close to zero (with the respective effect on current direction). As noted in the previous, the introduction of triad interactions results in a more significant effect when modelled with TELEMAC, although the SPB model does lead to smoother results regard- ing both speed and direction (run Tc34). Point PTc3 shows larger divergences than points PTc1 and PTc2 that attributed to the combination of its location in the computational domain and the significant shift in the forcing's direction after hour 6 (see Fig. 2). Figure 12 shows that at points PTc1 and PTc2 results are in good agreement for both TELEMAC and MIKE21, following the remark regarding the small $H_{\mathrm{S}}$ variations observed in the breaking zone for TS2 (see Fig. 11). At PTc3 TELEMAC results are similar to the MIKE21 ones between hours 3 and 7 but significantly higher at the beginning and the end of the simulated time series. 

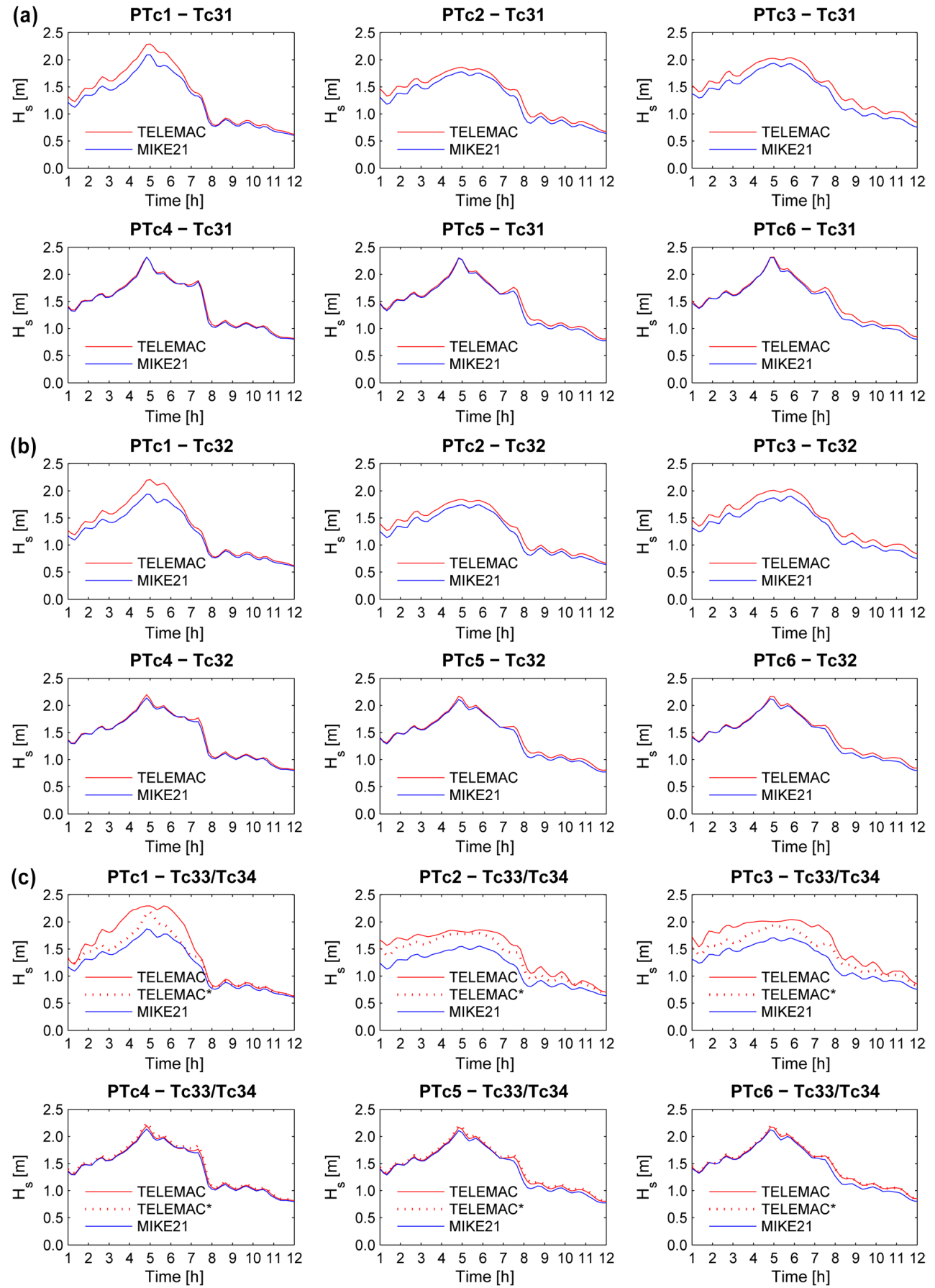

Figure 9. Comparison of TELEMAC and MIKE21 results $\left(H_{\mathrm{S}}\right)$ at points within $(\mathrm{PTc} 1, \mathrm{PTc} 2, \mathrm{PTc} 3)$ and outside of the breaker zone (PTc4, PTc5, PTc6) for the Brindisi-Torre Guaceto case study for runs (a) Tc31, (b) Tc32 and (c) Tc33/Tc34* .

Regarding the Bari case study, it should be stated again (as in Sect. 3.1.1) that the objective of its inclusion in this work was solely to test the extent to which spectral models could be used to capture diffraction effects near harbour entrances in the framework of operational approaches like the one presented in Sect. 3.2. This was done while keeping in mind the inherent limitations posed by the inclusion of diffraction in phase-averaged models, as well as the fact that a detailed study of harbour agitation would require the use of a phase-resolving model. Figure 13 shows TOMAWAC results (with and without the inclusion of diffraction) along transect TRh1 and as wave fields at the area of the harbour, for forcings WE1 (Fig. 13a, b and c respectively) and WE2 (Fig. 13d, e and f respectively). Results show noticeable dif- 

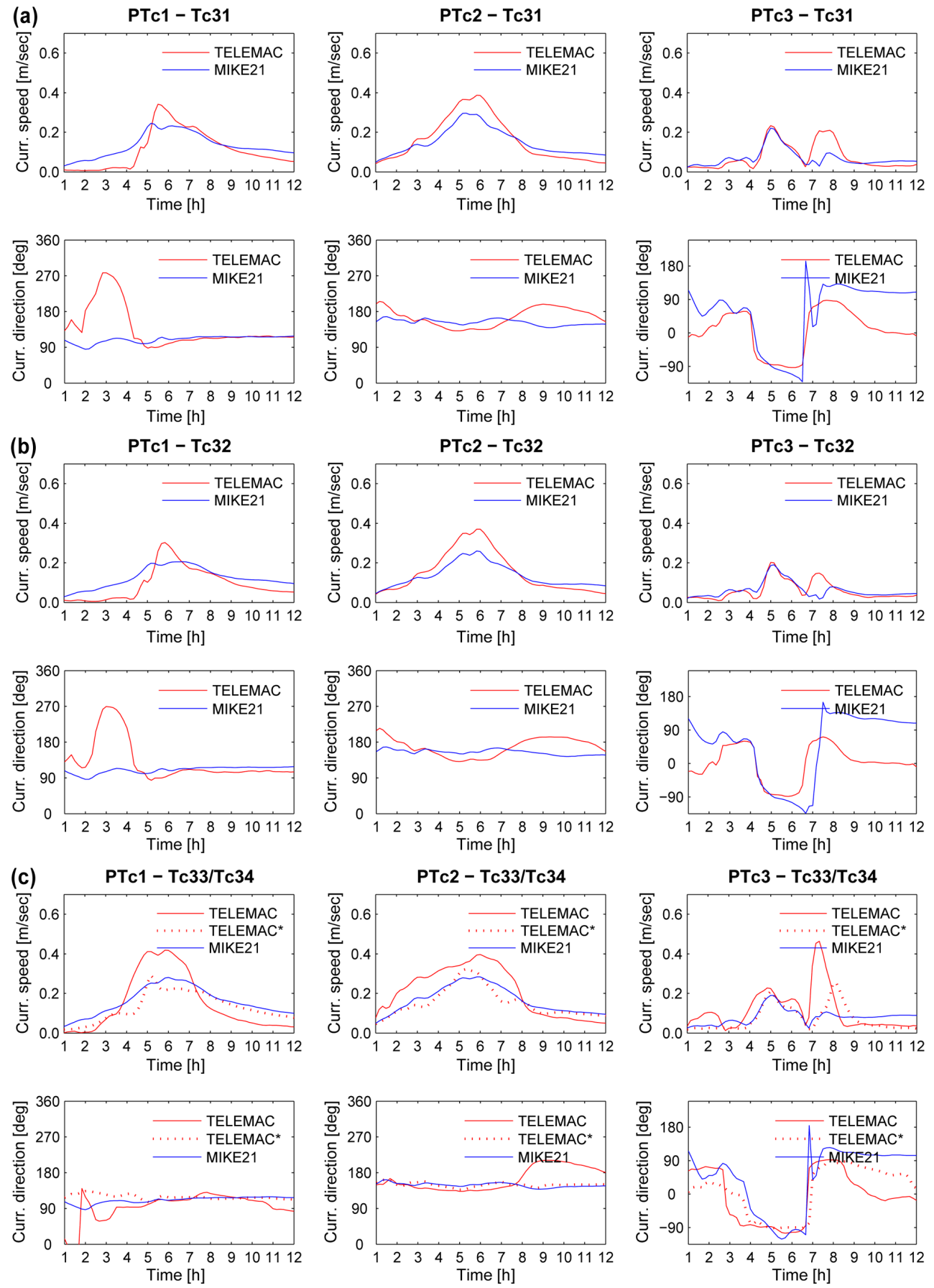

Figure 10. Comparison of TELEMAC and MIKE21 results (Curr. speed/direction) at points within the breaker zone (PTc1, PTc2, PTc3) for the Brindisi-Torre Guaceto case study for runs (a) Tc31, (b) Tc32 and (c) Tc33/Tc34*.

ferences in wave characteristics around the breakwater's tip and near the harbour entrance, while the model also manages to capture the diffusion of the wave height inside the harbour area; larger effects are observed for the higher-wave forcing WE1. Figure 14 shows TOMAWAC results (with and without the inclusion of diffraction) at points PTh1, PTh2 and PTh3 for forcings TS1 and TS2 (Fig. 14a and b respec- tively). Differences are noticeable for all parameters, being relatively more significant at points PTh2-PTh3 and for the higher-wave forcing TS2.

Finally, the multiparametric approach presented in this work was successfully implemented in the framework of the Italian Flagship Research Project TESSA, using WAVEWATCH III (Tolman, 2009) to feed sets of offshore wave 

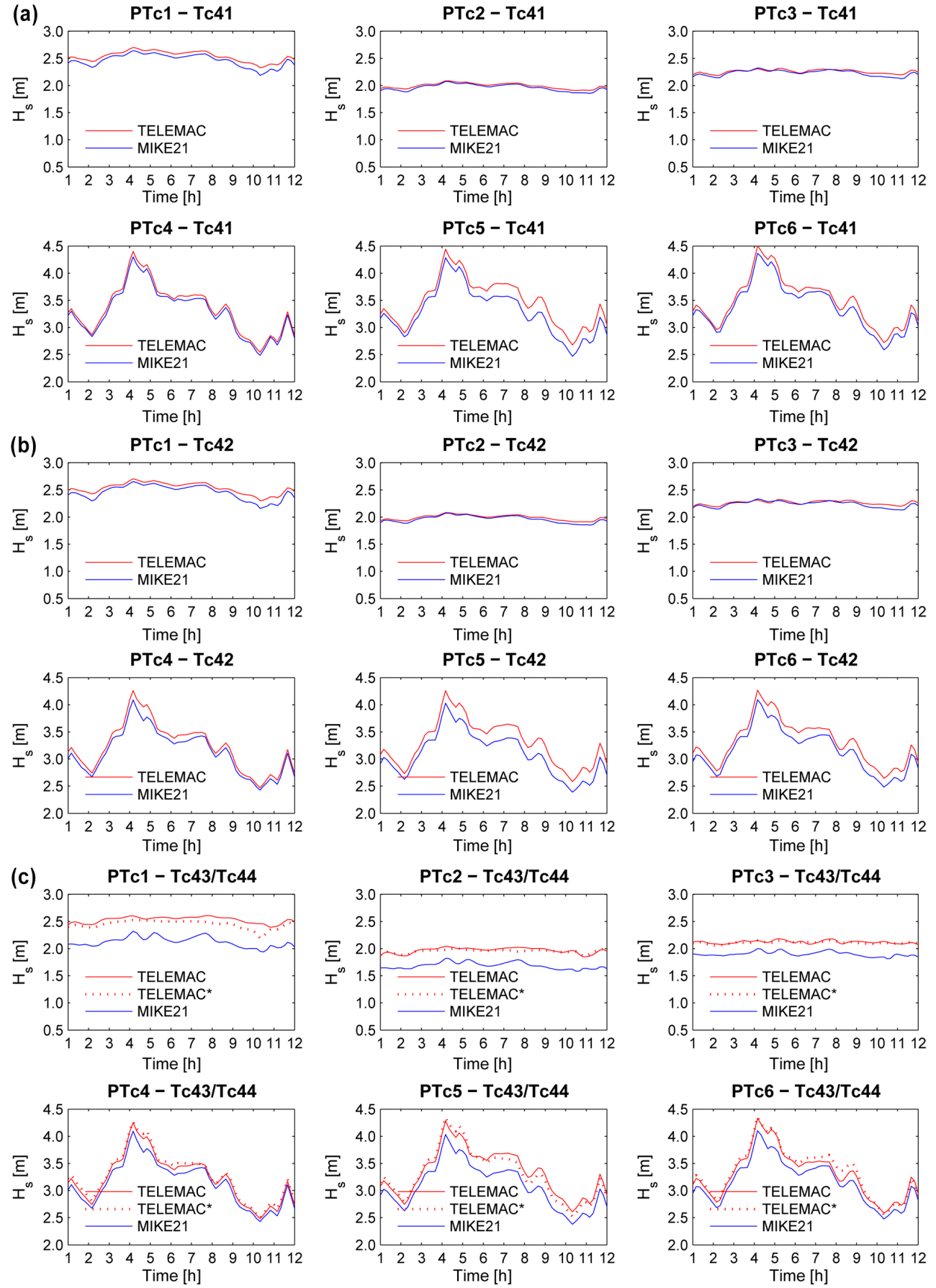

Figure 11. Comparison of TELEMAC and MIKE21 results $\left(H_{\mathrm{S}}\right)$ at points within $(\mathrm{PTc} 1, \mathrm{PTc} 2, \mathrm{PTc} 3)$ and outside of the breaker zone $(\mathrm{PTc} 4$, PTc5, PTc6) for the Brindisi-Torre Guaceto case study for runs (a) Tc41, (b) Tc42 and (c) Tc43/Tc44*.

characteristics to the query algorithm in order to provide nearshore wave conditions from the created database of MIKE-SW results. Its performance was tested for a series of different wave conditions for the three areas of interest (i.e. Brindisi, Bari and Gulf of Taranto; see Fig. 3) and the algorithm managed to deliver results in a fast and seamless way at all times.

\section{Conclusions}

This work presents the comparison of the TELEMAC and MIKE21 modelling suites in fundamental wave and hydrodynamics applications for the representation of nearshore dynamics and proposes a multiparametric scenario-based approach for the rapid assessment of wave conditions in coastal 

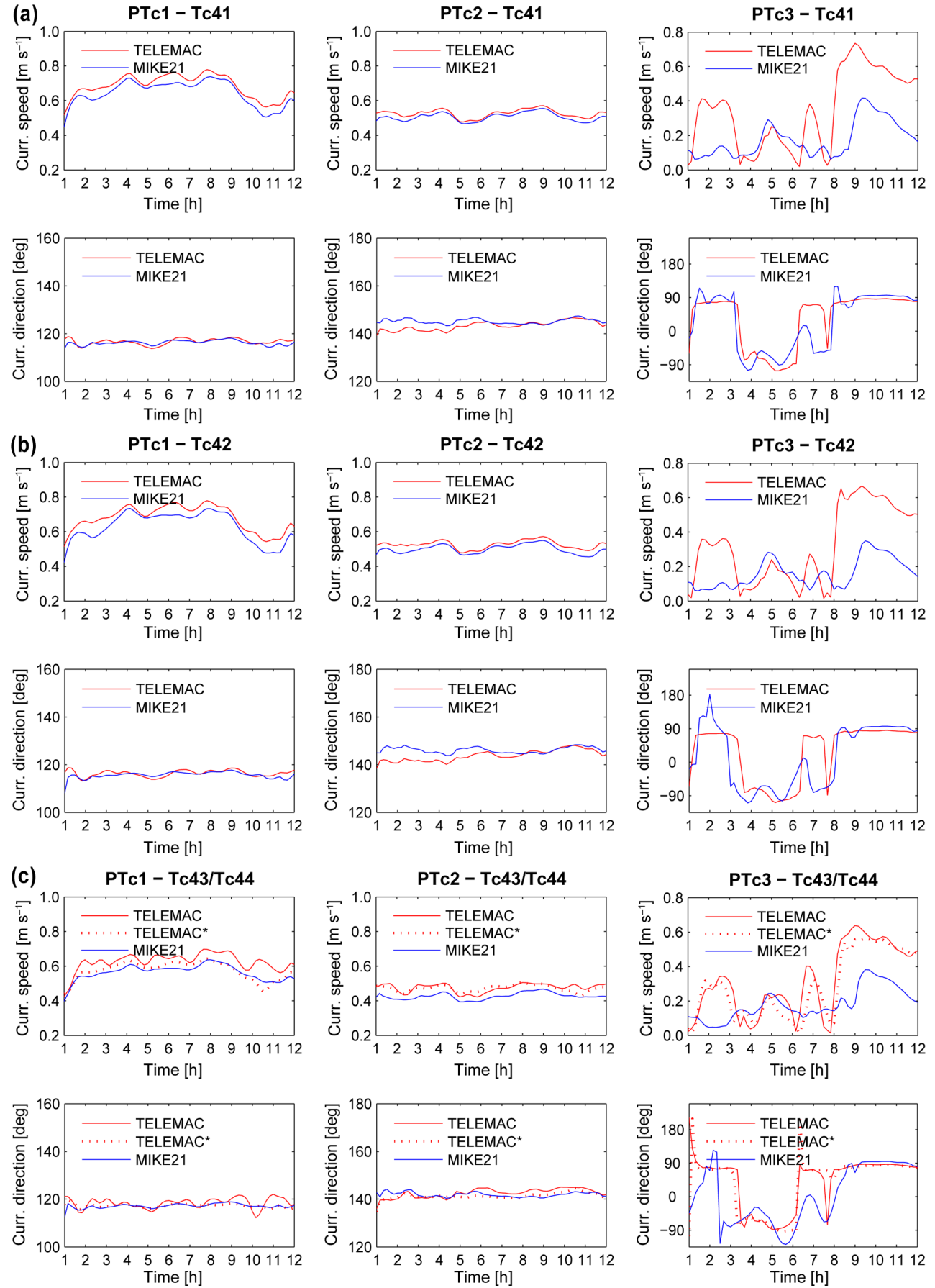

Figure 12. Comparison of TELEMAC and MIKE21 results (Curr. speed/direction) at points within the breaker zone (PTc1, PTc2, PTc3) for the Brindisi-Torre Guaceto case study for runs (a) Tc41, (b) Tc42 and (c) Tc43/Tc44*.

zones that aims to serve as an operational tool for coastal planning, decision support and assessment. The study areas for the presented applications are all located in South Italy and comprise the coastal area around the city/port of Brindisi, the coastal area around the city/port of Bari and the Gulf of Taranto. For the first one, TELEMAC and MIKE21 are intercompared for a series of application set-ups aiming to test the models' performance and the representation of the various processes governing wave propagation and wave-induced nearshore hydrodynamics. For the study area of Bari (including its harbour), the spectral wave model of TELEMAC (i.e. TOMAWAC) is applied with and without the inclusion of the representation of the processes of diffraction in order to test the extent to which similar models could be used to capture 

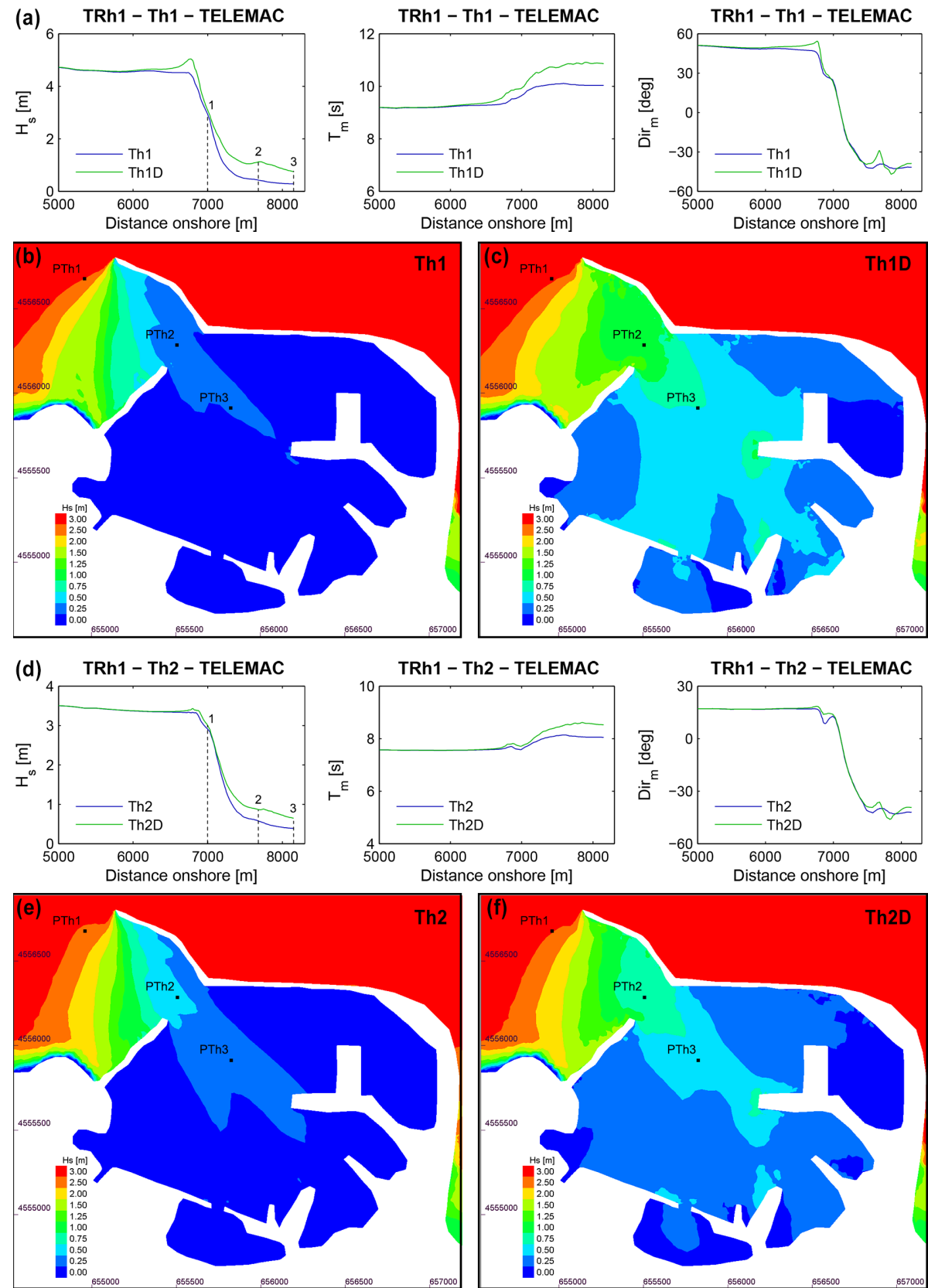

Figure 13. Comparison of TOMAWAC results for the Bari case study: (a, d) along transect TRh1 for forcings WE1 and WE2 respectively; $(\mathbf{b}, \mathbf{c})$ and $(\mathbf{e}, \mathbf{f})$ as wave fields at the harbour of Bari for forcings WE1 and WE2 respectively.

diffraction effects near harbour entrances, in the framework of operational approaches like the one presented in this work when the detailed agitation inside the harbour is not of interest. TELEMAC and MIKE21 results are compared on the basis of wave/current characteristics, along linear transects from the offshore to the nearshore and at specific points inside/outside the breaker zone and near the entrance of the harbour for the study area of Bari. Analysis shows an overall satisfactory agreement between the two modelling suites and is deemed to provide useful insights on both their in- dividual capabilities and their comparative evaluation. The specific tasks also served as the background study for the development of a modelling system based on a multiple-nesting approach, coupling atmosphere, ocean and coastal dynamics (described in Gaeta et al., 2016), while it also retains a strong user-oriented component, showing examples of how models perform under typical coastal application scenarios and how basic physical processes affect the computed parameters of interest. The proposed multiparametric approach is presented in detail, consisting of the definition of a number 

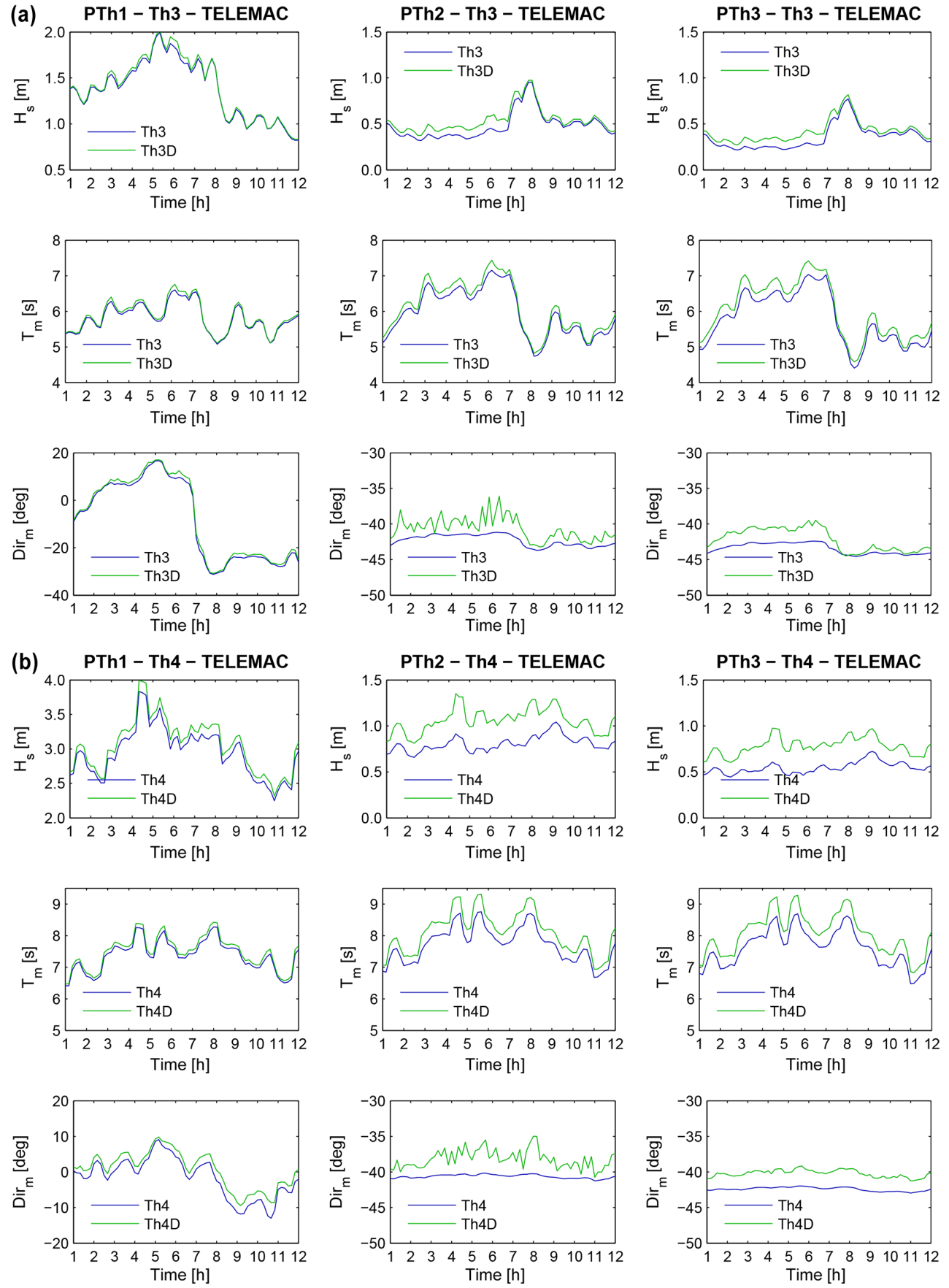

Figure 14. Comparison of TOMAWAC results $\left(H_{\mathrm{S}}-T_{\mathrm{m}}-\mathrm{Dir}_{\mathrm{m}}\right)$ for the Bari case study at points PTh1, PTh2 and PTh3 for forcings (a) TS1 and (b) TS2.

of wave scenarios on the basis of field measurements, a data set of wave model results using these scenarios as boundary conditions and a query algorithm based on the trilinear interpolation that bridges coarser-resolution operational models and the aforementioned data set in order to provide querytailored fields of nearshore wave dynamics. The implementation of the specific approach as part of an operational chain for all three study areas in South Italy in the framework of the Italian Flagship Project TESSA supports the rationale behind this study, while setting the basis for future work on the same path. 
Acknowledgements. This work was performed and funded in the framework of the Italian Flagship Project "TESSA - Development of Technologies for the Situational Sea Awareness" supported by the PON01_02823/2 "Ricerca \& Competitività 2007-2013" program of the Italian Ministry for Education, University and Research.

The authors would like to thank Andrea Pedroncini from DHI Italia and Antonio Bonaduce from the Euro-Mediterranean Center on Climate Change for their valuable help on various modelling aspects of the MIKE21 suite and on assisting with the operational implementation of the multiparametric approach in the framework of the TESSA Project respectively. The authors would also like to thank the Handling Editor Ivan Federico and the two referees for their constructive comments and suggestions.

Edited by: I. Federico

Reviewed by: C. Koutitas and one anonymous referee

\section{References}

Aboobacker, V. M., Vethamony, P., Sudheesh, K., and Rupali, S. P.: Spectral characteristics of the nearshore waves off Paradip, India during monsoon and extreme events, Nat. Hazards, 49, 311-323, doi:10.1007/s11069-008-9293-8, 2009.

Archetti, R., Paci, A., Carniel, S., and Bonaldo, D.: Optimal index related to the shoreline dynamics during a storm: the case of Jesolo beach, Nat. Hazards Earth Syst. Sci., 16, 1107-1122, doi:10.5194/nhess-16-1107-2016, 2016.

ArıGüner, H. A., Yüksel, Y., and Özkan Çevik, E.: Estimation of wave parameters based on nearshore wind-wave correlations, Ocean Eng., 63, 52-62, doi:10.1016/j.oceaneng.2013.01.023, 2013.

Babu, M. T., Vethamony, P., and Desa, E.: Modelling tidedriven currents and residual eddies in the Gulf of Kachchh and their seasonal variability: A marine environmental planning perspective, Ecol. Model., 184, 299-312, doi:10.1016/j.ecolmodel.2004.10.013, 2005.

Barnard, P., van Ormondt, M., Erikson, L., Eshleman, J., Hapke, C., Ruggiero, P., Adams, P., and Foxgrover, A.: Development of the Coastal Storm Modeling System $(\mathrm{CoSMoS})$ for predicting the impact of storms on high-energy, active-margin coasts, Nat. Hazards, 74, 1095-1125, doi:10.1007/s11069-014-1236-y, 2014.

Battjes, J. A. and Janssen, J. P. F. M.: Energy loss and set-up due to breaking of random waves, 16th International Conference on Coastal Engineering, 27 August-3 September 1978, Hamburg, Germany, 569-587, 1978.

Becq-Girard, F., Forget, P., and Benoit, M.: Non-linear propagation of unidirectional wave fields over varying topography, Coast. Eng., 38, 91-113, doi:10.1016/S0378-3839(99)00043-5, 1999.

Becq, F.: Extension de la modélisation spectrale des états de mer vers le domaine côtier, $\mathrm{PhD}$ thesis, Université de Toulon et du Var, La Garde, France, 251 pp., 1998.

Berkhoff, J. C. W.: Computation of combined refraction - diffraction, 13th International Conference on Coastal Engineering, 1014 July 1972, Vancouver, Canada, 471-490, 1972.

Bertotti, L. and Cavaleri, L.: Modelling waves at Orkney coastal locations, J. Marine Syst., 96-97, 116-121, doi:10.1016/j.jmarsys.2012.02.012, 2012.
Booij, N., Ris, R. C., and Holthuijsen, L. H.: A third-generation wave model for coastal regions: 1 . Model description and validation, J. Geophys. Res., 104, 7649-7666, doi:10.1029/98jc02622, 1999.

Bourke, P.: Interpolation methods, available at: http://paulbourke. net/miscellaneous/interpolation/, last access: February 2016, 1999.

Bozzi, S., Archetti, R., and Passoni, G.: Wave electricity production in Italian offshore: A preliminary investigation, Renew. Energ., 62, 407-416, doi:10.1016/j.renene.2013.07.030, 2014.

Brière, C., Abadie, S., Bretel, P., and Lang, P.: Assessment of TELEMAC system performances, a hydrodynamic case study of Anglet, France, Coast. Eng., 54, 345-356, doi:10.1016/j.coastaleng.2006.10.006, 2007.

Brown, J. M. and Davies, A. G.: Methods for medium-term prediction of the net sediment transport by waves and currents in complex coastal regions, Cont. Shelf Res., 29, 1502-1514, doi:10.1016/j.csr.2009.03.018, 2009.

Burcharth, H. F., Lykke Andersen, T., and Lara, J. L.: Upgrade of coastal defence structures against increased loadings caused by climate change: A first methodological approach, Coast. Eng., 87, 112-121, doi:10.1016/j.coastaleng.2013.12.006, 2014.

Camus, P., Mendez, F. J., Medina, R., and Cofiño, A. S.: Analysis of clustering and selection algorithms for the study of multivariate wave climate, Coast. Eng., 58, 453-462, doi:10.1016/j.coastaleng.2011.02.003, 2011.

Corsini, S., Inghilesi, R., Franco, L., and Piscopia, R.: Italian Waves Atlas, APAT-Università degli Studi di Roma 3, Rome, Italy, 134 pp., 2006.

Eldeberky, Y. and Battjes, J. A.: Parameterisation of triads interactions in wave energy models, Coastal Dynamics Conference '95, 4-8 September 1995, Gdansk, Poland, 140-148, 1983.

Gaeta, M. G., Samaras, A. G., Federico, I., and Archetti, R.: A coupled wave-3D hydrodynamics model of the Taranto Sea (Italy): a multiple-nesting approach, Nat. Hazards Earth Syst. Sci. Discuss., doi:10.5194/nhess-2016-95, in review, 2016.

Ge, J., Ding, P., Chen, C., Hu, S., Fu, G., and Wu, L.: An integrated East China Sea-Changjiang Estuary model system with aim at resolving multi-scale regional-shelf-estuarine dynamics, Ocean Dynam., 63, 881-900, doi:10.1007/s10236-013-0631-3, 2013.

Google Earth: Image ${ }^{\odot} 2016$ TerraMetrics, Data SIO, NOAA, U.S. Navy, NGA, GEBCO, 2016.

Hasselmann, K., Barnett, T. P., Bouws, E., Carlson, H., Cartwright, D. E., Enke, K., Ewing, J. A., Gienapp, H., Hasselmann, D. E., Kruseman, P., Meerburg, A., Müller, P., Olbers, D. J., Richter, K., Sell, W., and Walden, H.: Measurements of wind-wave growth and swell decay during the Joint North Sea Wave Project (JONSWAP), Deutsches Hydrographisches Institut, Hamburg, Ergänzungsheft zur Deutschen Hydrographischen Zeitschrift, Reihe A $\left(8^{\circ}\right)$, Nr. 12, 95 pp., 1973.

Hervouet, J.-M.: Hydrodynamics of Free Surface Flows: Modelling with the finite element method, John Wiley \& Sons Ltd, New Jersey, USA, 360 pp., 2007.

Holthuijsen, L. H., Herman, A., and Booij, N.: Phase-decoupled refraction-diffraction for spectral wave models, Coast. Eng., 49, 291-305, doi:10.1016/S0378-3839(03)00065-6, 2003.

Idier, D., Rohmer, J., Bulteau, T., and Delvallée, E.: Development of an inverse method for coastal risk management, Nat. Hazards 
Earth Syst. Sci., 13, 999-1013, doi:10.5194/nhess-13-999-2013, 2013.

Janssen, P. A. E. M.: Quasi-linear Theory of WindWave Generation Applied to Wave Forecasting, J. Phys. Oceanogr., 21, 1631-1642, doi:10.1175/15200485(1991)021<1631:qltoww>2.0.co;2, 1991.

Jia, L., Wen, Y., Pan, S., Liu, J. T., and He, J.: Wave-current interaction in a river and wave dominant estuary: A seasonal contrast, Appl. Ocean Res., 52, 151-166, doi:10.1016/j.apor.2015.06.004, 2015.

Karambas, T. V.: Modelling of climate change impacts on coastal flooding/erosion, ports and coastal defence structures, Desalination and Water Treatment, 54, 1-8, doi:10.1080/19443994.2014.934115, 2014.

Karambas, T. V. and Samaras, A. G.: Soft shore protection methods: The use of advanced numerical models in the evaluation of beach nourishment, Ocean Eng., 92, 129-136, doi:10.1016/j.oceaneng.2014.09.043, 2014.

Komen, G. J., Hasselmann, K., and Hasselmann, K.: On the Existence of a Fully Developed Wind-Sea Spectrum, Journal of Physical Oceanography, 14, 1271-1285, doi:10.1175/15200485(1984)014<1271:oteoaf>2.0.co;2, 1984.

Kong, X.: A numerical study on the impact of tidal waves on the storm surge in the north of Liaodong Bay, Acta Oceanol. Sin., 33, 35-41, doi:10.1007/s13131-014-0430-9, 2014.

Kreyszig, E.: Advanced Engineering Mathematics, John Wiley \& Sons, Inc., New Jersey, USA, 2010.

Long, J. W., Plant, N. G., Dalyander, P. S., and Thompson, D. M.: A probabilistic method for constructing wave time-series at inshore locations using model scenarios, Coast. Eng., 89, 53-62, doi:10.1016/j.coastaleng.2014.03.008, 2014.

Luo, J., Li, M., Sun, Z., and O'Connor, B. A.: Numerical modelling of hydrodynamics and sand transport in the tidedominated coastal-to-estuarine region, Mar. Geol., 342, 14-27, doi:10.1016/j.margeo.2013.06.004, 2013.

O'Reilly, W. C. and Guza, R. T.: A comparison of two spectral wave models in the Southern California Bight, Coast. Eng., 19, 263 282, doi:10.1016/0378-3839(93)90032-4, 1993.

Ozer, J., Padilla-Hernández, R., Monbaliu, J., Alvarez Fanjul, E., Carretero Albiach, J. C., Osuna, P., Yu, J. C. S., and Wolf, J.: A coupling module for tides, surges and waves, Coast. Eng., 41, 95-124, doi:10.1016/S0378-3839(00)00028-4, 2000.

Plant, N. G. and Holland, K. T.: Prediction and assimilation of surf-zone processes using a Bayesian network: Part II: Inverse models, Coast. Eng., 58, 256-266, doi:10.1016/j.coastaleng.2010.11.002, 2011a.
Plant, N. G. and Holland, K. T.: Prediction and assimilation of surf-zone processes using a Bayesian network: Part I: Forward models, Coast. Eng., 58, 119-130, doi:10.1016/j.coastaleng.2010.09.003, 2011b.

Porter, D.: The mild-slope equations, J. Fluid Mech., 494, 51-63, 2003.

Ranasinghe, R., Larson, M., and Savioli, J.: Shoreline response to a single shore-parallel submerged breakwater, Coast. Eng., 57, 1006-1017, doi:10.1016/j.coastaleng.2010.06.002, 2010.

Regione Puglia: Il clima meteomarino sul litorale pugliese, Regione Puglia - Assessorato Trasparenza e Cittadinanza Attiva, 355 pp., 2009.

Reikard, G.: Forecasting ocean wave energy: Tests of time-series models, Ocean Eng., 36, 348-356, doi:10.1016/j.oceaneng.2009.01.003, 2009.

Rusu, L. and Soares, C. G.: Local data assimilation scheme for wave predictions close to the Portuguese ports, Journal of Operational Oceanography, 7, 45-57, 2014.

Sauvaget, P., David, E., and Guedes Soares, C.: Modelling tidal currents on the coast of Portugal, Coast. Eng., 40, 393-409, doi:10.1016/s0378-3839(00)00020-x, 2000.

Siegle, E., Huntley, D. A., and Davidson, M. A.: Coupling video imaging and numerical modelling for the study of inlet morphodynamics, Mar. Geol., 236, 143-163, 2007.

Stockdon, H. F., Doran, K. J., Thompson, D. M., Sopkin, K. L., Plant, N. G., and Sallenger, A. H.: National assessment of hurricane-induced coastal erosion hazards-Gulf of Mexico, U.S. Geological Survey, Open-File Report 2012-1084, 51 pp., 2012.

Tolman, H. L.: User manual and system documentation of WAVEWATCH III version 3.14, NOAA/NWS/NCEP/MMAB, 194 pp., 2009.

van Duin, M. J. P., Wiersma, N. R., Walstra, D. J. R., van Rijn, L. C., and Stive, M. J. F.: Nourishing the shoreface: observations and hindcasting of the Egmond case, The Netherlands, Coast. Eng., 51, 813-837, doi:10.1016/j.coastaleng.2004.07.011, 2004.

Villaret, C., Hervouet, J. M., Kopmann, R., Merkel, U., and Davies, A. G.: Morphodynamic modeling using the Telemac finite-element system, Comput. Geosci., 53, 105-113, doi:10.1016/j.cageo.2011.10.004, 2013.

Warner, J. C., Armstrong, B., He, R., and Zambon, J. B.: Development of a Coupled Ocean-Atmosphere-Wave-Sediment Transport (COAWST) Modeling System, Ocean Model., 35, 230-244, doi:10.1016/j.ocemod.2010.07.010, 2010. 